\title{
Experience-driven meaning affects lexical choices during language production
}

Anne Vogt ${ }^{1,2}$, Barbara Kaup ${ }^{3}$ \& Rasha Abdel Rahman ${ }^{1,2}$

1 Department of Psychology, Humboldt-Universität zu Berlin

2 Berlin School of Mind and Brain

3 University of Tübingen

Corresponding authors:

Anne Vogt, anne.vogt.1 @hu-berlin.de, Rudower Chaussee 18, 12489 Berlin

Rasha Abdel Rahman, rasha.abdel.rahman@hu-berlin.de, Rudower Chaussee 18, 12489 Berlin

Note: This is the authors' preprint version of the article (date: 05.09.2022). The final article has been accepted for publication in Quarterly Journal of Experimental Psychology (https://doi.org/10.1177/17470218221125425).

\begin{abstract}
The role of meaning facets based on sensorimotor experiences is well-investigated in comprehension but has received little attention in language production research. In two experiments, we investigated whether experiential traces of space influenced lexical choices when participants completed visually-presented sentence fragments (e.g., 'You are at the sea and you see a ...') with spoken nouns (e.g., 'dolphin', 'palm tree'). The words were presented consecutively in an ascending or descending direction, starting from the center of the screen. These physical spatial cues did not influence lexical choices. However, the produced nouns met the spatial characteristics of the broader sentence contexts such that the typical spatial locations of the produced noun referents were predicted by the location of the situations described by the sentence fragments (i.e., upper or lower sphere). By including distributional semantic similarity measures derived from computing cosine values between sentence nouns and produced nouns using a web-based text corpus, we show that the meaning dimension of 'location in space' guides lexical selection during speaking. We discuss the relation of this spatial meaning dimension to accounts of experientially grounded and usage-based theories of language processing and their combination in hybrid approaches. In doing so, we contribute to a more comprehensive understanding of the many facets of meaning processing during language production and their impact on the words we select to express verbal messages.
\end{abstract}

Key Words: Language Production, Experiential Traces, Language Grounding, Hybrid Models, Lexical Selection, Semantic Processing

\section{Acknowledgements}

This work was supported by the Berlin School of Mind and Brain and a doctoral fellowship by the Studienstiftung des deutschen Volkes (German National Academic Foundation) awarded to Anne Vogt. We thank Eduard Berndt for providing the data set of spatial ratings with 250 German nouns used for the control words. We are grateful to Fritz Günther for help 
with implementing and discussing the analyses which are based on distributional similarity measures. Furthermore, we thank Tabea Villinger for supporting stimulus preparation and data collection of Experiment 2 and Guido Kiecker for technical support. All authors developed the study design, discussed the results and wrote the manuscript. Anne Vogt performed data collection and analyses. 
A central process during language production is the selection of the right words to express an intended meaning. While the role of some meaning aspects like categorical relations - is well investigated, little is known about others (Abdel Rahman \& Melinger, 2019). Specifically, and in contrast to language comprehension, little is known about meaning aspects grounded in sensorimotor experiences. This is surprising because we frequently talk about our sensations and experiences in everyday life. Therefore, meaning aspects linked to our sensory experiences seem fundamental in language production.

The present study was designed to investigate influences of experientially grounded meaning on lexical-semantic processing during language production. Furthermore, we relate sensorimotor experiences to a measure of semantic similarity by using linguistic distributional measures of meaning relations.

\section{Semantic relations in language production}

When speakers plan to produce a message, meaning representations at the conceptual level and word representations at the lexical level (lemmas) - as well as semantically related conceptual and lexical entries - are activated, and the target lemma is selected from among these co-activated alternatives (Caramazza, 1997; Dell, 1986; Levelt et al., 1999; Mahon et al., 2007; Oppenheim et al., 2010). Evidence of lexical-semantic factors influencing lexical selection stems from context effects induced by displaying constraining vs. nonconstraining sentences before asking individuals to name a picture (Hustá et al., 2021), from context effects by previouslynamed related pictures (e.g., in the cyclic blocking and continuous naming paradigm; Belke, Meyer, \& Damian, 2005; Howard, Nickels, Coltheart, \& Cole-Virtue, 2006), or simultaneously-presented related distractor words (in the picture word interference paradigm; e.g. Glaser \& Düngelhoff, 1984; for a recent discussion, see Roelofs, 2018; Bürki, Elbuy, Madec, \& Vasishth, 2020). Typically, categorical semantic relations have been investigated in these paradigms. However, the meaning of verbal messages is multifaceted and may as well contain information about associations, part-whole-relations, thematic links, as well as social and emotional meaning aspects. Therefore, it should not be reduced to categorical relations (Abdel Rahman \& Melinger, 2019, Jackson, Hoffman, Pobric, \& Lambon Ralph, 2015), but investigations of non-categorical relations during lexical selection are comparatively rare and have focused on thematic, situational or associative relations (Abdel Rahman \& Melinger, 2007, 2019; Alario et al., 2000; Aristei \& Abdel Rahman, 2013; Costa et al., 2005; Damian \& Spalek, 2014; de Zubicaray et al., 2013; La Heij et al., 1990; Lin et al., 2021; Rose \& Abdel Rahman, 2016). Crucially, lexicalsemantic processing is not confined to traditionally investigated semantic relations, and may include a much wider range of meaning facets based on sensory experiences like aspects of sound, shape and color which have been shown to play a role during language production (de Zubicaray et al., 2018; Mädebach et al., 2018; Redmann et al., 2014).

\section{Experientially grounded representations in language comprehension}

Experiential grounding refers to the idea that the multimodal - and often bodily - experiences we have made leave 
experiential traces in our brain and become tied to our knowledge about these objects, situations or actions (Barsalou, 2008) and, consequently, to the linguistic constructions and words used in those situations (e.g. Lynott, Connell, Brysbaert, Brand, \& Carney, 2020; Zwaan \& Madden, 2005). Due to its strong link to bodily sensations, this line of work is often referred to as embodiment or embodied cognition. We use the phrase 'experiential grounding' throughout this paper in order to highlight that not all experiences are based on bodily sensations. From this perspective, concepts can be understood as modalityspecific, experience-dependent and flexible representations in distributed neural networks which include, but are not restricted to, sensorimotor areas of the brain (Kiefer \& Pulvermüller, 2012). Accessing these concepts as, for example, when retrieving word meanings involves a partial reactivation of the same brain processes that are active when experiencing the objects, situations or actions to which these concepts refer. This is also referred to as experiential simulation (Barsalou, 1999; Pecher \& Zwaan, 2005). These semantic effects occur within 100-200ms after presentation of verbal stimuli, nearsimultaneously to a range of psycholinguistic processes during comprehension (Pulvermüller et al., 2009), and can therefore not be reduced to postcomprehension processes (Hoenig, Sim, Bochev, Herrnberger, \& Kiefer, 2008). Furthermore, sensorimotor activations are modulated by context, allowing for a high degree of flexibility and fluency in the language comprehension system (Aravena et al., 2014; Hoenig et al., 2008).

There is ample evidence that experientially grounded meaning plays an essential role in conceptual knowledge (e.g., Binder \& Desai, 2011) and language comprehension (for overwiews see Bergen, 2015; Kaup, de la Vega, Strozyk, \& Dudschig, 2015; Meteyard, Cuadrado Rodriguez, Bahrami, \& Vigliocco, 2012; Pulvermüller, 2018).

\section{Language-space associations}

A particularly well-investigated domain of experiential grounding in language comprehension are languagespace associations in the vertical dimension. Spatial locations do not by themselves form a natural category and there is no a priori thematic or associative link between objects sharing the same space within the upper or lower sphere (e.g., between 'kite', 'bird's nest' and 'crown' as objects typically found in the upper sphere of our world). Therefore, experiential traces of space seem particularly well suited to investigate the role of situational and experientially grounded meaning during language processing, as spatial locations can easily be inferred but are an implicit aspect of meaning. Due to reactivations of actual experiences during concept acquisition, processing nouns referring to objects with a typical location in space leads to an orientation of attention towards this location (e.g., Dudschig, Lachmair, de la Vega, De Filippis, \& Kaup, 2012; Estes, Verges, \& Barsalou, 2008; Öttl, Dudschig, $\&$ Kaup, 2017). These reactivations of experiential traces of space are tied to simulations of contexts or events in which an object typically appears and cannot be deduced to abstract meaning features like 'up' or 'down' (Ostarek and Vigliocco, 2017). Furthermore, spatial cues linked to situations can facilitate the accessibility of words, as has been shown in an anagram solving task (Berndt et al., 2018). Most studies on language-space associations 
have focused on spatial compatibility effects where the dependent measure bears spatial characteristics, such as an up- or downward movement (Lachmair et al., 2011), thus investigating an effect of language on non-linguistic tasks. Further, some studies used non-linguistic cues and investigated whether this influenced concurrent language processing. For example, Lachmair and colleagues (2016) changed the body position of their participants between an upright or a headdown position. They found that participants remembered more up-words in the up-right position and more down-words in the headdown position. In another study, vertical visual motion of dots on a screen had an impact on a lexical decision task when participants were presented with verbs denoting upward or downward movement like 'rise' or 'fall' (Dudschig et al., 2013; Meteyard et al., 2008). Thus, perception of motion can influence language comprehension (see also Kaschak et al., 2005), hinting at a link between visual and semantic processes.

\section{Experiential Grounding and Language Production}

While experiential grounding in comprehension is well-investigated (see above), comparatively little is known about the potential role of experientially grounded meaning in language production, and it is unclear whether experiential traces are among the meaning factors that determine which lexical candidates are selected for articulation.

Two of the few studies suggesting that experientially grounded motor information may influence subsequent language production used a cyclic naming paradigm. In this paradigm, visually depicted actions were blocked according to their effector (hands/arms vs. feet) and an interference effect for naming action verbs was found (de Zubicaray et al., 2017; Hirschfeld \& Zwitserlood, 2012). In a second experiment by Hirschfeld and Zwitserlood (2012) participants were asked to produce action verbs for depicted actions while executing a concurrent motor task. When the effector of a depicted action (e.g. foot for the activity of jumping) matched the effector which had to be used for the concurrent motor task, interference in naming was observed, too. However, according to Hirschfeld and Zwitserlood, the results are also compatible with the view, that abstract foot- or hand-related semantic features were co-activated by the movements, spreading to abstract effectorrelated concepts like e.g. 'part of the lower extremities', 'has toes/fingers', 'used for walking/manipulating objects' which then lead to competition between activated lexical nodes (see also Vigliocco et al., 2002). Therefore, they argue that their findings might not be interpreted as clearcut evidence for a direct functional role of experientially grounded conceptual representations in language production.

Similar results have been obtained in other picture naming tasks. Investigating the motor domain, Witt, Kemmerer, Linkenauger, and Culham (2010) asked their participants to squeeze a ball in one hand, slowing down the naming of tools whose handles faced the squeezing hand compared to naming animals (but see Matheson, White, and McMullen, 2014). In an object naming task which was combined with a concurrent manual task, an increase in object naming errors was found which was related to the degree of experience subjects had in touching the depicted objects: for frequently manipulated objects naming was more difficult when the 
concurrent motion task engaged the hands in a way which would make interaction with the real object impossible (Yee, Chrysikou, Hoffman, \& Thompson-Schill, 2013; for similar results using rTMS see Pobric, Jefferies, \& Ralph, 2010).

Furthermore, patients with motionrelated neurological diseases, like Parkinson's, show increased difficulties in verb-naming tasks as the degree of motor content of the depicted actions increases (Herrera et al., 2012).

Asking participants to provide a verbal label for a given definition, Fargier, Montant, and Strijkers (2019) found that words which are strongly grounded in sensorimotor and/or emotional experiences are retrieved faster than words which are lesser-grounded, irrespective of their concreteness. These results seem to support the importance of experientially grounded meaning aspects for lexical retrieval.

Taken together, few studies have investigated experientially grounded meaning in language production. Among those, some have investigated the role of experiential meaning in conceptual representations in general, employing mainly naming tasks, but without directly focusing on language production (Matheson et al., 2014; Mulatti et al., 2014; Sixtus et al., 2018; Witt et al., 2010; Yee et al., 2013). Furthermore, other studies provide little or inconsistent evidence concerning the role of experiential traces in lexical selection. Firstly, it is still unclear whether the involvement of sensorimotor simulations during picture naming is necessary (de Zubicaray et al., 2017; Hirschfeld \& Zwitserlood, 2012). Secondly, the activation of sensorimotor traces seems to be highly context specific (Ben-Haim et al., 2015; Matheson et al., 2014). Moreover, there is evidence for both facilitation and interference of lexical access when providing information boosting experiential simulations (de Zubicaray et al., 2017; Hirschfeld \& Zwitserlood, 2012; Mulatti et al., 2014; Sixtus et al., 2018; Witt et al., 2010). This pattern mirrors the findings in language comprehension research, where both interference and facilitation effects have been reported. However, to date, a clear and encompassing theory for these patterns still seems to be missing (Ostarek \& Huettig, 2019). Therefore, the role of experientially grounded meaning aspects during lexical selection remains unclear.

\section{Combining experientially grounded meaning aspects with distributional semantics}

So-called hybrid models are theories of semantic memory which integrate accounts of meaning based on experiential grounding with accounts based on distributional semantics. Theories of distributional semantics assume that the statistical regularities in natural languages are taken up by the cognitive system and are transferred into semantic representations which reflect the use of language (see below for more detail). According to the distributional hypothesis "you shall know a word by the company it keeps" (Firth, 1957), the meaning of a word can be deduced by the linguistic context in which it occurs. This idea has been implemented in different kinds of computational models quantifying meaning similarity between words by computing co-occurrence vectors (for an overview see e.g. Günther, Rinaldi, \& Marelli, 2019; Sahlgren, 2008; Wingfield \& Connell, 2019). While implementations of distributional semantic models approximate human performance in many different tasks, they lack 
psychological plausibility as they can't explain how concepts acquire meaning, which has also come to be known as the symbol grounding problem (Harnad, 1990; Searle, 1980). On the other hand, experiential accounts of meaning tend to disregard the importance of non-sensory and non-motoric sources of semantic knowledge.

Theories of distributional semantics and theories of embodiment or experiential grounding of semantics have often been treated as separate while a combination of these accounts in fact helps our understanding of semantic memory (Davis $\&$ Yee, 2021). Given that we learn concepts not only from direct sensory experience but also merely by being immersed in language given a sufficiently large directly-grounded vocabulary (Louwerse, 2018) it becomes evident that the often-conceived gap between language-based distributional models of semantics and experientially grounded accounts of meaning is more dichotomous than necessary. Language use as reflected in large text corpora captures many aspects of our bodily and sensory experiences as we use language to communicate about them (Durda et al., 2009) and therefore, sensorimotor contingencies are not only part of our direct experience but are also mirrored in distributional language use (Zwaan \& Madden, 2005). Furthermore, we are able to learn about bodily and sensory experiences merely by being exposed to linguistic descriptions of these without first-hand experience but still yielding typical effects of experiential re-activation (Günther et al., 2018, 2020) pointing to the fact that oral and written language can in fact serve as just another source of experience. These observations lead to several calls for reconciling grounded and distributional accounts of meaning (Andrews et al., 2014; Davis \& Yee, 2021).

In summary, language is used to communicate about the world and our experiences in the world and therefore it is not independent from it. Distributional semantics which rely on the statistical regularities in language use therefore often also contain information about sensorimotor experiences (Louwerse, 2011). However, the correspondence between the our direct sensorimotor experiences of the physical world and the experiential information extracted from language use alone is not $1: 1$. There are meaning aspects which can only be inferred from one of these sources (for a detailed discussion of the relation between sensorimotor grounded meaning and distributional semantics see Günther et al., 2019) and at least part of our mental lexicon needs to be directly grounded (VincentLamarre et al., 2015). This claim is backed up by increasing evidence that sensorimotor and distributional-linguistic meaning aspects are interacting but distinct types of knowledge.

For example, Carota et al. (2021) found a widely distributed network of active brain regions during silent reading. Importantly, activity in brain regions relevant for semantic selection and combinatorial semantic processes correlated with a distributional model of the stimulus set while cortical regions associated with sensorimotor processing responded more strongly to the experiencebased characteristics of the stimulus set.

While it is acknowledged that insights into the nature of semantic representations - which have mostly been gained by investigating language comprehension - should be incorporated into language production research (Vinson 
et al., 2014), neither theories based on distributional language usage nor experientially grounded theories - or a combination of both - played an important role in the investigation of lexical selection processes. Only recently, Banks and colleagues (2021) asked participants to produce category members for given semantic categories. They found that both the order and the frequency of produced words can be predicted by measures of linguistic and sensorimotor similarity. These findings were also integrated into a computational model which performed most accurately with indirect spread of activation between categories and when sensorimotor and linguistic distributional aspects of meaning were accounted for. This is one of the first pieces of evidence suggesting that speakers make use of the experiential and linguistic contexts in which words occur and that they contribute separately when it comes to lexical selection.

However, an explicit integration of various aspects of meaning in language production models is still lacking (Abdel Rahman \& Melinger, 2019; Vinson et al., 2014) and we know little about the role of distinct types of information from which word meaning can be learned (Louwerse, 2018; Vigliocco et al., 2009).

\section{The present study}

This study was designed to test whether experientially grounded meaning aspects have an influence on which words we select when we prepare to speak and in how far they are influenced by distributional aspects of meaning. We combined the existing paradigms from the comprehension literature which show that physical visual stimulation has an influence on the processing of spatially connotated words (Berndt et al., 2018; Dudschig et al., 2013; Kaschak et al., 2005; Meteyard et al., 2008; Ostarek \& Vigliocco, 2017) with the evidence for automatic re-activation of spatial meaning when processing up- and down-related words and sentences (Bergen et al., 2007; Dudschig et al., 2012; Estes et al., 2008; Lachmair et al., 2011; Lachmair, Dudschig, et al., 2016; Lachmair, Ruiz Fernández, \& Gerjets, 2016; Ostarek et al., 2018; Öttl et al., 2017; Thornton et al., 2013; Vogt et al., 2019). We developed a paradigm which enables us to investigate whether activations of language-space associations - for which there is ample evidence in language comprehension - can be found in language production, too. To this end, we employed a free production task and manipulated both the visual presentation mode (up- vs. downward movement of sentences) and the spatial content of the stimulus sentences (describing different locations in space). In contrast to previous studies investigating the duration of lexical selection processes (e.g. Hustá, Zheng, Papoutsi, \& Piai, 2021), we asked WHICH words are selected based on contexts that pose little or no semantic constraints. Participants were asked to complete written sentence fragments (e.g., 'You are strolling across the field and you see ...') by orally producing a noun of their choice. The fragments extended upwards or downwards from the center of the screen, with each word being presented above or below the previous word.

As visual input has been shown to influence the processing of words with spatial connotations, we assumed that visual stimulation also influences lexicalsemantic processing during language production. We expected lexical choices for completing the sentence fragments to be influenced by visuo-spatial manipulation; 
that is, the location of the produced nouns should be predicted by the upward or downward movement of the sentence fragments. In other words, participants should complete a sentence like 'You are hiking through the forest and you see a...' with a noun like 'bird', referring to an entity that is typically found in the sky, after having read an ascending sentence, and with a noun like 'fox' after having read a descending sentence.

Additionally, we examined influences of the spatial location of the situation described by the sentences, investigating whether the typical location of the produced nouns can be predicted by the spatial connotations of the sentences. After sentences denoting situations which are perceived as occupying a higher physical space like 'You are in the mountains...', we expected nouns to refer to entities in the upper sphere and vice versa.

Moreover, we estimated the degree of semantic similarity between the produced noun and the noun in the sentence fragment using cosine values as a distributional measure of similarity (Günther et al., 2015). Semantic similarities are computed based on text corpora, and meaning relations of words that tend to occur in similar texts may capture different semantic relations as categorical, associative or thematic links (Durda et al., 2009). Therefore, we used the distributional measure of similarity to obtain an estimate of semantic relatedness that captures the traditionally investigated semantic relations known to influence lexical selection during language production in semantic context paradigms. By relating our experiential spatial manipulations to a measure of semantic relatedness, we addressed the question of how experientially grounded and linguistic distributional semantic meaning aspects relate to each other in a production task with given sentence contexts.

\section{Experiment 1}

\section{Methods}

Participants. We recruited 35 native German speakers using the institutes' participant pool Psychologischer Experimental Server Adlershof (PESA). The data of two participants was removed prior to analysis due to a high number of missing or invalid answers (less than $60 \%$ of remaining trials). The final sample consisted of 33 participants (24 females, 18 - 33 years, $M_{\text {age }}=25.82, S D_{\text {age }}=4.56$ ) who provided written informed consent prior to participation. The study was conducted according to the principles expressed in the Declaration of Helsinki and was approved by the local Ethics Committee. Participants received either course credit or monetary compensation.

Stimuli. 90 German sentences like 'Du spazierst über das Feld und siehst eine ...' (English: 'You are strolling across the field and you see a ...') or 'Du gehst zu der Haltestelle und siehst einen ...' (English: 'You are walking towards the bus stop and you see a ...') were used as stimuli. All sentences had a similar structure and were incomplete. The $1^{\text {st }}$ position of each sentence consisted of the personal pronoun 'you'. At the $2^{\text {nd }}$ position, 30 verbs of motion (of which nine were stative verbs, e.g., 'walk', 'stroll', 'run', 'sit', 'stand') were used; thus, each verb appeared in three different sentences. The $3^{\text {rd }}$ position consisted of a local preposition, followed by a definite article at the $4^{\text {th }}$ position. The $5^{\text {th }}$ position constituted a noun containing the relevant information regarding the 
scene of the described event. Nouns were only used once and referred to an individual's destination or places where a person can move around (e.g., 'street', 'field', 'bus stop', 'forest', 'lake', 'train station'). The sentences continued with the conjunction 'and' at the $6^{\text {th }}$ position and a verb of perception at the $7^{\text {th }}$ position ('see', 'spot', 'discover'), each repeated 30 times across all sentences. At the $8^{\text {th }}$ position, there was an indefinite article. As accusative articles in German signify gender, we counterbalanced the distribution of neutral, female and male articles over six experimental lists, assuring that each sentence was paired with each article equally often across participants and experimental conditions. After the indefinite article, the sentences ended with an ellipsis to prompt participants to complete the sentence. We ensured that a wide range of endings was possible for each sentence, i.e. sentences were not constraining as for example in cloze paradigms (Block \& Baldwin, 2010). We used 40 filler sentences with a similar structure as our experimental sentences. The ending for some fillers was intended to be more easily predictable in order to make the task easier for participants. Six additional sentences were used in practice trials.

Sentence spatial location. Before starting the main experiment, we conducted an online rating of the spatial locations of our sentences using the platform https://www.soscisurvey.de. Nine voluntary participants who did not take part in the main experiment ( 6 females, 22 - 67 years, $\left.\quad M_{\text {age }}=31.78, \quad S D_{\text {age }}=13.63\right)$ indicated on a 7-point Likert scale where the places denoted by the noun at the $5^{\text {th }}$ sentence position are in space (see below for more information on spatial ratings).
These values served as a measure of the spatial location of the scenes denoted by the sentences. These values were later added into our analysis in order to analyze the impact of the sentence location on the choice of a suitable sentence ending. A list of all sentences with their respective spatial location values are presented in Appendix A.

Procedure. Before starting the experiment, we told our participants that we were investigating language processing of speakers with different native languages (Arabic, Chinese and German) as a cover story. We deemed it common knowledge that Arabic and Chinese differ from German regarding reading direction and wanted to keep participants from wondering why stimuli were presented in an unusual reading direction in order to minimize the risk of participant's guessing the aim of the task.

Participants were seated in a dimly lit room approximately $70 \mathrm{~cm}$ in front of a computer screen with a resolution of $1280 \times 1024$ pixels. Sentences were displayed consecutively in Rapid Serial Visual Presentation mode using Presentation ${ }^{\circledR}$ software (Version 17, Neurobehavioral Systems, Inc., Berkeley, CA, www.neurobs.com). The experiment started with a practice block consisting of six sentences. During the experiment, participants were able to take small breaks after blocks of fifteen sentences.

Each sentence was presented once during the experiment and participants saw each sentence either in ascending or descending presentation direction. Filler sentences were presented in the same way. Within each list, test sentences and fillers were presented in a random order. We presented each word for $300 \mathrm{~ms}$ in black on 
a grey background in Arial 24pt font. Each trial started with a fixation cross appearing in the center of the screen for $500 \mathrm{~ms}$. Then the first word appeared in the center of the screen. The following word replaced the previous word and appeared either 35 pixels higher or lower than its predecessor. Thus, the position of the three dots was 315 pixels above or below the screen center and 197 pixels apart from the edge of the screen. The dots remained on screen for $4000 \mathrm{~ms}$; afterwards there was a blank screen for $2000 \mathrm{~ms}$ before the next trial started. Participants were instructed to read the sentences silently and to complete the sentences with a suitable noun as spontaneously and quickly as possible as soon as the ellipsis appeared. Participants were asked to orally produce only one word in each trial and to avoid repeating the same noun several times throughout the experiment. We recorded answers given in the time frame of $6000 \mathrm{~ms}$ after the ellipsis appeared (see Figure 1 for illustration of a trial sequence). The experimenter monitored the experiment from another room and immediately noted the answers.

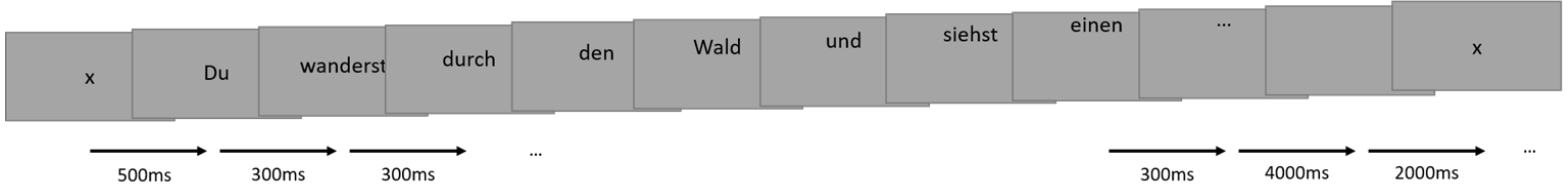

Figure 1. Trial sequence with an example of an upward moving sentence (English: 'You are walking through the forest and you see ...') and a participant producing the noun 'bird'. Note that screen position was fixed in the experiment and only moves upwards in the figure for illustrative purposes.

\section{Rating of spatial attributes of} produced nouns. In a second step, after running the sentence completion study, spatial attributes for the produced nouns were obtained to assess whether the choice of the produced nouns had been influenced by the experimental manipulation. To this end, the produced nouns entered a rating study. Nouns uttered by several participants were included only once (e.g. several people used the word 'bird', albeit some used it in different contexts throughout the experiment). Nouns which presumably have the same referent - but where participants used different lexemes to convey a comparable meaning - entered the rating in all the forms which had been produced during the experiment (e.g., 'Schiffsanleger' vs. 'Bootsanleger',
English roughly 'jetty' vs. 'pier'). In case of ambiguous nouns, a short description of their lexical meaning was added. For example, as could be inferred from the context, the word 'Sirene' had not been intended to refer to the English 'siren', but to the mythological figure of a mermaid. Therefore, raters saw this noun as 'Sirene (Fabelwesen)', English: 'siren, mythological figure'. The complete set of produced words was reduced to a set of 1056 rated words implemented similarly to Díez-Álamo, Diéz, Wojcik, Alonso, and Fernandez (2018) and Scott, Keitel, Becirspahic, Yao, and Sereno (2019). In order to reduce the time for the rating for each rater, each rater only saw a subset of the total word set. To this end, the produced nouns were randomized and then distributed on 21 questionnaires, with the 
first questionnaire containing words 1-352, the second questionnaire containing words 51-402, the third questionnaire containing words 101-452, etc., thereby ensuring that the questionnaires were representative of the whole set of produced nouns. Additionally, 20 control words were added to each questionnaire. These control words had not been produced in the sentence completion study but were taken from an unpublished set of spatial ratings for German nouns, spanning the entire range of locations where entities can be encountered, from very high up ('Sternschnuppe', English: 'falling star') to very low (' $U$ Boot', English: 'submarine'). The questionnaires were administered using the online platform https://www.soscisurvey.de. In each trial, a target word was selected randomly and displayed with a vertical 7-point rating scale ranging from 'up' to 'down' (with 'centrally' at the midpoint) below it. Additionally, participants could skip the rating of a word in case the spatial property could not be judged. By clicking one of the points on the scale, participants had to judge where the object referred to by the noun can typically be found. The approximate time to complete the rating was 20 minutes. In total, 37 voluntary participants who did not take part in the production experiment (22 females, 23 - 59 years, $\left.\quad M_{\text {age }}=35.76, \quad S D_{\text {age }}=9.61\right)$ were randomly assigned to one of the questionnaires. The procedure of assigning different questionnaires to participants ensured that each target word received ratings from at least 9 subjects. Assuming that ratings for control words whose spatial location was based on previous rating data are an indicator of subject's compliance, intra-class correlation between the previous rating data and each rater was computed using the function ICC from the R-package psych (Revelle, 2018), as suggested by Hallgren (2012) and Trevethan (2017). The agreement with the existing mean rating values for the control words was $\operatorname{ICC}(3,1)$ $\geq .72$ for all raters and the intra-class correlation between all subjects was excellent following the criteria of Fleiss (1986), $\operatorname{ICC}(3,1)=.83$. Therefore, none of the ratings were excluded, and ratings for all but the control nouns were averaged across raters, yielding one rating value for each distinct noun. This served as an indicator of the spatial location of the entity denoted by that noun. Ratings were merged with the data from the sentence completion study so that for each trial a mean spatial rating serving as an indicator of the spatial location of the produced noun was obtained.

\section{Data Analysis}

Data was analyzed using the free statistics software R Version 3.6.1 (R Core Team, 2017). The data set consisted of 2970 data points (33 participants completing 90 sentences). Missing trials in which participants did not produce a noun were excluded (12.2\% of all trials). Afterwards, erroneous trials (incomplete, unintelligible, and nonsensical answers as well as utterances which consisted of more than one word or in which participants simply repeated the noun of the sentence which they had read) were excluded from further analysis (2.9\% of all trials). Additionally, eight trials had to be excluded for missing spatial rating values due to experimenter error. Trials in which participants produced nouns whose gender did not match the gender required by the article were not excluded from analysis as some participants seemed to have ignored the gender of the article. There were many instances of masculine nouns being 
produced after neutral articles, which is incorrect from a grammatical point of view. However, the masculine accusative article 'einen' is typically shortened to 'ein' in colloquial speech, equaling the neutral article. Thus, it cannot be safely concluded that participants ignored the gender of the article in those cases, as they might have silently pronounced the written sentences before giving an answer aloud. The phonological similarity of 'einen' and 'ein' in spoken German might have led them to produce nouns of both neutral and male gender, respectively. In total, a set of 2515 utterances remained for statistical analysis.

In order to assess the influence of the experimental manipulation on the spatial properties of the produced nouns, a linear mixed model was computed with the packages lme4 (Bates et al., 2015) and lmerTest (Kuznetsova et al., 2017). We started with a maximal model containing interactions between the fixed predictors presentation direction and centered spatial location values for the nouns of the sentence fragments, as well as by-subject and by-item random intercepts and slopes. Sliding difference contrasts were applied for the predictor presentation direction. Random effects were simplified in case of singular fit or convergence problems, resulting in the final model containing bysubject and by-item random intercepts only. Using model comparison, this model was compared to one containing additive fixed effects for presentation direction and centered spatial location values. We report beta-estimates together with a $95 \%$ confidence interval estimated with the Wald method, as well as $t$ - and $p$-values.

\section{Results}

Numerically, there was almost no difference in mean spatial ratings between nouns produced after ascending vs. descending sentences $\quad\left(M_{\text {up }}=3.577\right.$, $\left.M_{\text {down }}=3.582\right)$. This finding was corroborated using a linear mixed model containing additive effects for presentation direction and spatial location values for stimuli, which explained the data better than a model containing interactions $\left(C h i^{2}(1)=.971\right)$. There was no main effect for presentation direction $(\beta=-0.01[-0.10$; $0.07], t=-0.26, p=.80)$, but there was a significant main effect of sentence spatial location $(\beta=0.20[0.11 ; 0.28], t=4.69$, $p<.001)$, indicating that the spatial locations of the situations presented by the sentence fragments influenced the spatial attributes of the produced nouns, see Figure $2 .{ }^{\mathrm{i}}$ 


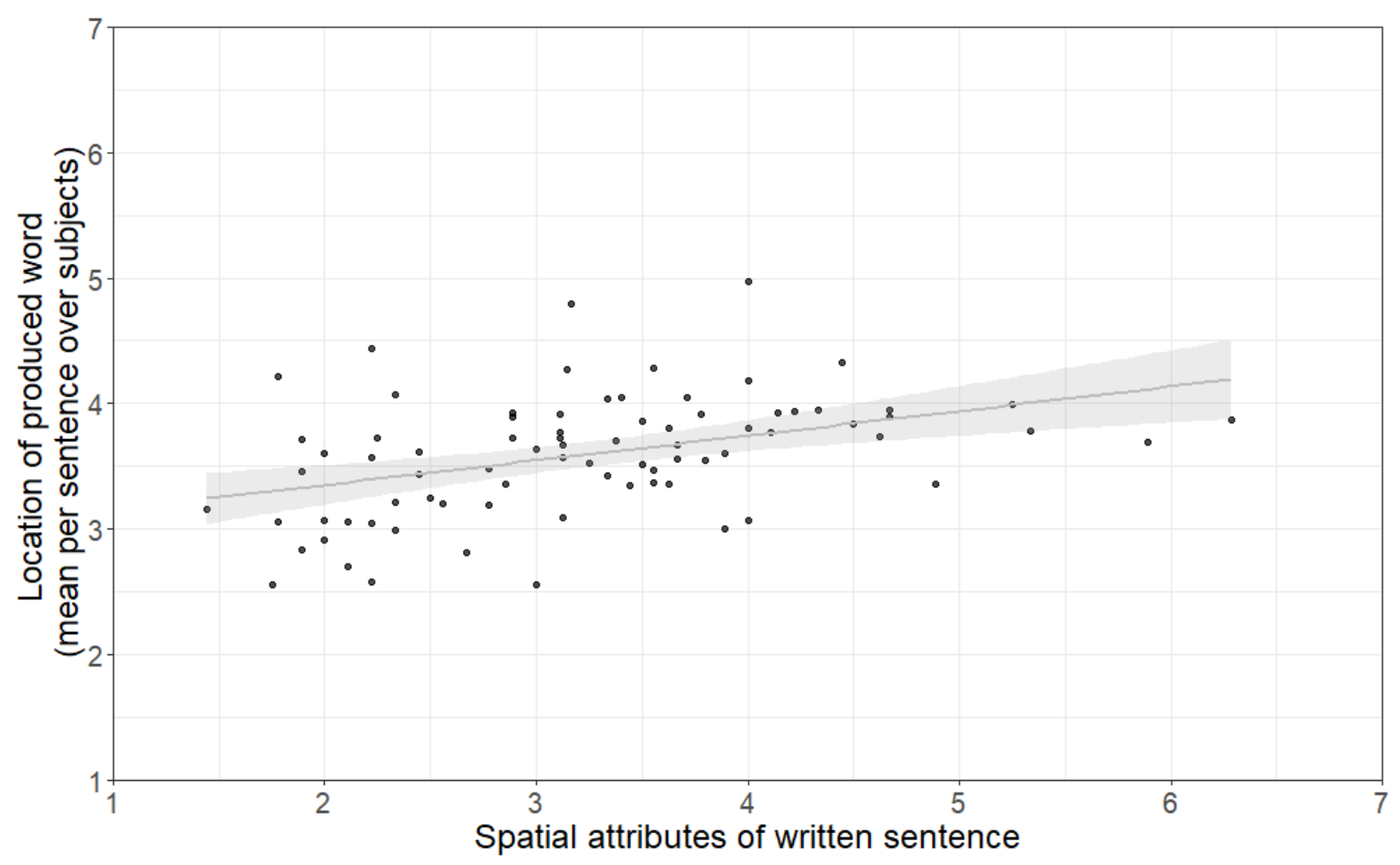

Figure 2. The spatial location of nouns in the sentence fragments predicts the location of the noun referents chosen as suitable sentence endings. The line depicts the effect as estimated in the linear models, the dots represent mean spatial values of the produced words for each sentence fragment respectively. Spatial locations of the entities referred to with the produced nouns were rated on a scale ranging from 1 (down) to 7 (up) after the experiment. Spatial locations of nouns in the sentence were rated on a scale ranging from 1 (down) to 7 (up) before the experiment. For illustrative purposes, sentence noun spatial locations are not centered.

To gain further insights into the relation between this effect and traditionally investigated semantic measures known to affect conceptualsemantic processing during language production, we included a distributional measure of semantic similarity between the nouns in the presented sentences and the produced nouns as a covariate in the analysis. We used the semantic space dewak100k_cbow (Günther et al., 2015) built from the deWaC-corpus by using the cbow algorithm as implemented in the word2vec model (Mikolov et al., 2013). The deWaC corpus is a 1.7 billion word corpus constructed from the Web limiting the crawl to the de domain and using medium-frequency words from the Süddeutsche Zeitung corpus and basic German vocabulary lists as seeds (Baroni et al., 2009). Cosine values were computed for each pair of $5^{\text {th }}$ sentence position and produced nouns using the package LSAfun (Günther et al., 2015). These cosine values serve as an indicator of semantic similarity, with higher values indicating that the two respective words more often occur together in similar contexts than others and have a highly similar meaning.

Because not all words were included in the used corpus, cosine values could not be computed for all cases. 
Furthermore, trials with cosine values less than zero were not used for subsequent analyses as these cosine values cannot be interpreted in a meaningful way (Günther et al., 2015). Thus, the reduced data set with similarity measures consisted of 1904 out of 2515 total nouns which had been used for the first linear mixed model analysis. Centered cosine values were entered into the linear model as an additional predictor with main effects for direction and an interaction between cosine values and centered sentence spatial location values, as well as random intercepts for items and subjects. There was no interaction between semantic similarity as indexed by cosine values and sentence spatial location values $(\beta=0.08[-0.35 ; 0.50], t=0.36, p=.72)$. Thus, the effect of sentence spatial location on spatial properties of the produced nouns cannot be explained by similarity, see Figure 3.

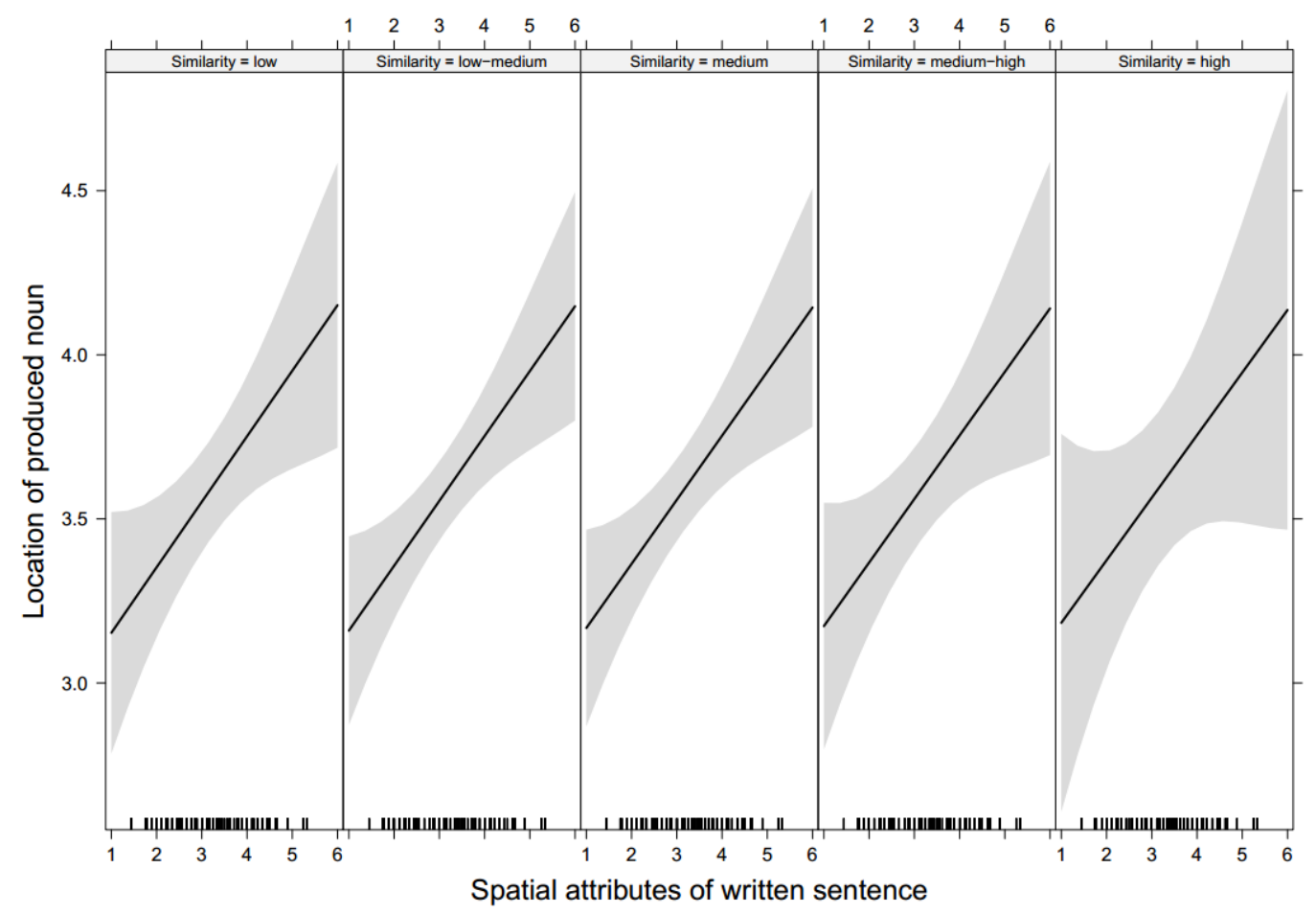

Figure 3. Effect plot showing that increasing degrees of semantic similarity between the noun in the presented sentence and the produced noun did not influence the spatial attributes of the presented sentences. Higher values for location of the produced noun as well as for spatial attributes of the written sentences indicate a higher localization in space. Small ticks above the $\mathrm{x}$-axis mark the distribution of the set of sentences regarding their spatial properties. For illustrative purposes, sentence spatial locations are not centered. The continuous predictor of similarity was split into five points of equal distance. Low and high similarity refer to the lowest vs. highest cosine values obtained in this study; they are used as descriptive labels while no pre-defined level of degrees of semantic similarity regarding cosine values exists.

Again, there was no effect of direction but a significant main effect of sentence spatial location $(\beta=0.20[0.10$; $0.29], t=4.07, \quad p<.001)$. For similar results obtained with the semantic space de_wiki, see supplement S1. 


\section{Discussion}

There was no influence of the manipulation of presentation direction on the spatial properties of the produced nouns. Therefore, our hypothesis that visual spatial manipulation in the form of a physical spatial cue affects lexical selection was not confirmed. However, there was an influence of the experientially driven meaning dimension 'location in space' on the choice of nouns. When considering the typical spatial location of the situations described by the sentence fragments, the spatial properties of the produced nouns could be predicted. Thus, the more a sentence referred to a situation in the upper or lower domain of the world, the higher up or lower down the referents of the produced nouns were located. For example, after the sentence 'You lean at the window and you see a...' which had been rated as being found in the upper sphere, the nouns people produced tended to be more upward related like 'bird' or 'rainbow' as when people completed sentences like 'You jump over the tree trunk and you see a...' which had been rated as being in the lower sphere and where people were more likely to produce words as 'rainworm' or 'hole' which are also more downward related in comparison to upward related words like 'bird's nest'. This might demonstrate that experiential traces of space are reactivated during language processing and influence subsequent lexical selection. We will discuss this interpretation in the General Discussion section.

However, many participants reported that the task was difficult for them, reflecting the high number of lost and invalid trials (15.1\%, see Methods). We had aimed to prevent participants from preparing a possible answer prior to reaching the end of the sentence by also presenting an indefinite article. As German articles determine gender in the accusative case, participants had to wait until they read the article before a lexical choice could be made. Thereby, we wanted to maximize the impact of the visual manipulation and prevent participants from preparing their answer in advance. However, this manipulation made it difficult to come up with suitable nouns, as time for completing a sentence was limited and led to omissions, neglecting the case of the article, or - as in about $20 \%$ of all trials - naming a person. This was a wide-spread strategy in order to fulfil the gender requirements of the article. For instance, participants could say 'Polizist' in case of the male article 'einen' (English: 'policeman') and 'Polizistin' in case of the female article 'eine' (English: ' policewoman'). However, naming a person is not informative about the spatial attributes of a noun, as persons are usually found in the central plane and occupy the same space as a person experiencing the situation described by the sentence. The large number of trials in which a noun referring to a person was produced may have reduced the impact of the movement manipulation. In Experiment 2, we therefore presented sentence fragments with no articles.

\section{Experiment 2}

Experiment 2 was a preregistered study using the Open Science Framework (https://osf.io/se6a3/?view_only=f666716d 3b8f47228017b9dadc6e2950) designed to replicate the findings of Experiment 1. To reduce task complexity and trial loss, words were presented for slightly longer and sentences didn't end with an article. Thus, participants were asked to produce a 
determiner noun phrase and were not restricted in their selection of suitable nouns regarding gender. Furthermore, we introduced a baseline condition in which sentences were presented in the center of the screen. We also improved the stimulus set by balancing the sentence spatial location values of the sentence fragments across the different presentation directions. Additionally, the number of participants was increased to enhance the chances of detecting even small effects of the movement manipulation on lexical selection.

\section{Methods}

Only those aspects differing from the first experiment will be described below.

Participants. We recruited 78 native German speakers. ii Data of two participants was removed prior to analysis as their German language proficiency was limited despite reporting being native speakers. Furthermore, the data of four other participants was excluded due to not following the instructions $(\mathrm{N}=2)$ or a high number of missing or invalid answers $(\mathrm{N}=2)$. The final sample consisted of 72 participants (49 females, 18 - 35 years, $\left.M_{\text {age }}=25.60, \quad S D_{\text {age }}=4.93\right)$. Participants provided written informed consent prior to participation. The study was conducted according to the principles expressed in the Declaration of Helsinki and was approved by the local Ethics Committee. Participants received either course credit or monetary compensation.

Stimuli. 60 German sentences with a similar structure as in the first experiment were used as stimuli, e.g., 'Du läufst zum Feld und siehst ...' (English: 'You are walking towards the field and you see ...'). Compared to the first experiment, only four verbs of motion ('stand', 'walk', 'go', 'enter') and the verb 'be' were used at the $2^{\text {nd }}$ position, appearing equally often across the full set of sentences. The $3^{\text {rd }}$ position consisted of a definitive article or a local preposition contracted with a definite determiner (e.g., 'am' - 'at the', 'zur' 'towards the'). At the $4^{\text {th }}$ position, a noun conveying the relevant information about the location at which the scene happened was used. The sentences finished with the conjunction 'and' at the $5^{\text {th }}$ position and a verb of perception at the $6^{\text {th }}$ position. The sentence display terminated with an ellipsis '...', serving as a prompt for the participants to complete the sentence with a suitable noun. Furthermore, we constructed 24 filler trials with a similar structure and the same number of words as the sentences. Six additional sentences were used in practice trials.

Sentence spatial location. Before starting the main experiment, we conducted an online rating of the spatial location of our sentences using the platform https://www.soscisurvey.de. Fifteen voluntary participants who did not take part in the main experiment ( 8 females, 27 - 71 years, $\left.\quad M_{\text {age }}=34.00, \quad S D_{\text {age }}=10.76\right)$ indicated on a 9-point Likert-scale where the places denoted by the noun at the $4^{\text {th }}$ sentence position are in space. ${ }^{\text {iii }}$ Apart from adding them as predictors into our analysis, the sentence spatial location values were used to construct experimental lists. All sentences with their respective sentence spatial location values are presented in Appendix B.

Procedure. Mean rating values were computed for each of the sentence nouns ranging from 2.4 ('Kanal'/'canal') to 7.7 ('Aussichtspunkt'/'vantage point'). Afterwards, three sentences with nouns of a similar mean rating value were combined 
into a triplet with the goal of minimizing the difference in mean rating values between nouns in the same triplet. The resulting difference was 0.31 or less, with a mean difference of 0.08 between the nouns of an adjacent sentence pair. Each participant read each sentence fragment from each triplet. Each participant saw each sentence of a triplet only once in one of the three presentation directions. Presentation direction and triplets were counterbalanced over nine lists so that every sentence was presented equally often in the same direction across participants. This resulted in every participant reading sentence fragments with similar spatial location values in each condition. Thereby, we controlled potential impacts of spatial locations on our stimuli with regard to the manipulation of presentation direction.

Each trial started with a fixation cross presented for $500 \mathrm{~ms}$, after which each word was presented for $400 \mathrm{~ms}$. Each sentence ended with an ellipsis, serving as an indicator that participants should complete the sentence. After $4 \mathrm{sec}$, a circle was presented in the center of the screen. Then participants could start the next trial in a self-paced manner by pressing the space bar on the keyboard. Responses were recorded within a window of $6 \mathrm{sec}$ after the appearance of the ellipsis. The first word of a sentence always appeared in the center of the screen. The following word appeared either at the same position, 47 pixels above or below that original position, or replaced the previous word at the center. The position of the ellipsis was 329 pixels above or below screen center and 183 pixels apart from the edge of the screen. Participants were instructed to read each sentence fragment and to spontaneously produce a noun to end the sentence as quickly as possible and, if necessary, with appropriate determiner. We asked them to not complete the sentences by repeating parts of the sentence or by producing nouns describing a person (e.g., 'a woman', 'a bus driver', 'a neighbor'). The experimenter monitored the experiment in the same room behind a folding screen, noting participants' answers on a sheet of paper.

Rating of spatial attributes of produced nouns. In order to minimize the total number of words entering the rating, nouns with the same - or very similar referents entered the rating only in one form, assuming that the spatial properties of the referents of these almost synonymous words would be the same. Additionally, nouns produced several times by different participants entered the rating only once. ${ }^{\text {iv }}$ Thus, the total number of produced nouns was reduced to 915 words divided into 10 questionnaires, each containing 457 or 458 words as well as 20 additional control words. Data from one rater was excluded prior to computing mean spatial ratings, as the intra class correlation coefficient with the control words - which was only in the fair range $(\operatorname{ICC}(3,1)=.58)$ - indicated that this participant did not follow the instructions. Therefore, data from 30 participants (19 females, $18-76$ years, $\left.M_{\text {age }}=33.57, S D_{\text {age }}=13.82\right)$ was used to compute mean spatial rating values, with each target word having been rated by at least 13 subjects. Mean spatial ratings were merged with the data from the sentence completion study in order to obtain a numeric indicator of the spatial location of each produced word.

\section{Data Analysis}

The data set consisted of 4320 data points (72 participants completing 60 sentences). Trials in which participants didn't produce a noun ( $2.4 \%$ of all trials), 
as well as erroneous trials $(1.4 \%$ of all trials) and trials in which participants produced a noun describing a person, were excluded (4.2\% of all trials). Additionally, 13 trials for which no spatial ratings were obtained due to experimenter error were excluded from further analysis. Based on our preregistered criteria, all trials including the sentence 'You are at the harbor and you see...' were excluded from analysis because more than $50 \%$ of the participants chose the same noun to complete the sentence. After preprocessing, the data set consisted of 3893 nouns.

Like Experiment 1 and based on the preregistered analysis plan, we analyzed the data with a maximal model containing interactions between the fixed predictors presentation direction and centered spatial location values for the nouns of the sentence fragments as well as by-subject and by-item random intercepts and slopes. Sliding difference contrasts were applied for the predictor presentation direction (three levels: descending, central, ascending). Random effects were simplified in case of singular fit or convergence problems which resulted in the final model containing by-subject and by-item random intercepts only. Using model comparison, this model was compared to one containing additive fixed effects for presentation direction and centered spatial location values.

\section{Results}

As in Experiment 1, a model containing additive effects for presentation direction and spatial location values for stimuli explained the data best $\left(C h i^{2}(2)=.876\right)$. Contrary to our hypothesis, nouns produced after ascending sentences were located lower in space $\left(M_{u p}=3.64\right)$ than nouns produced after sentences with unchanging position $\left(M_{\text {central }}=3.79\right)$, resulting in a significant main effect for the contrast of ascending vs. central presentation direction in the linear mixed model $(\beta=-0.15[-0.24 ;-0.07]$, $t=-3.51, \quad p<.001)$. There was no significant main effect for the contrast of descending vs. central presentation direction $(\beta=0.07[-0.02 ; 0.15], t=1.50$, $p=.133$ ), see Figure 4. Furthermore, and converging with results from Experiment 1, there was a significant effect for sentence spatial location values $(\beta=0.28[0.19$; $0.37], t=6.32, p<.001$ ), indicating that the locations of the sentence fragments influenced the spatial attributes of the produced nouns, see Figure 5. 


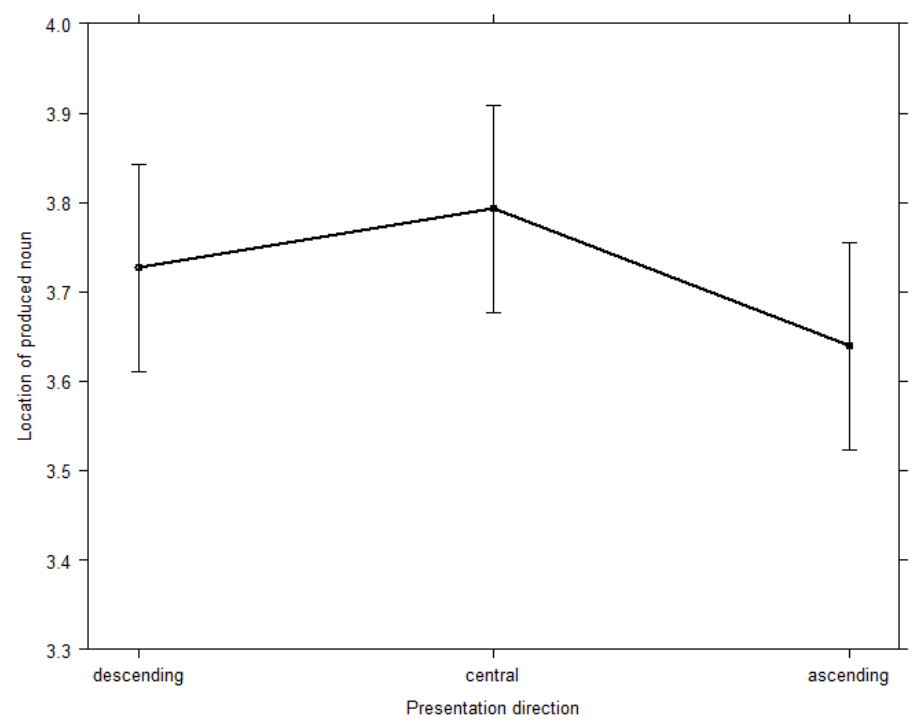

Figure 4. Estimated means and $95 \%$ confidence band for spatial locations of the produced nouns depending on the presentation direction of sentence fragments in Experiment 2.

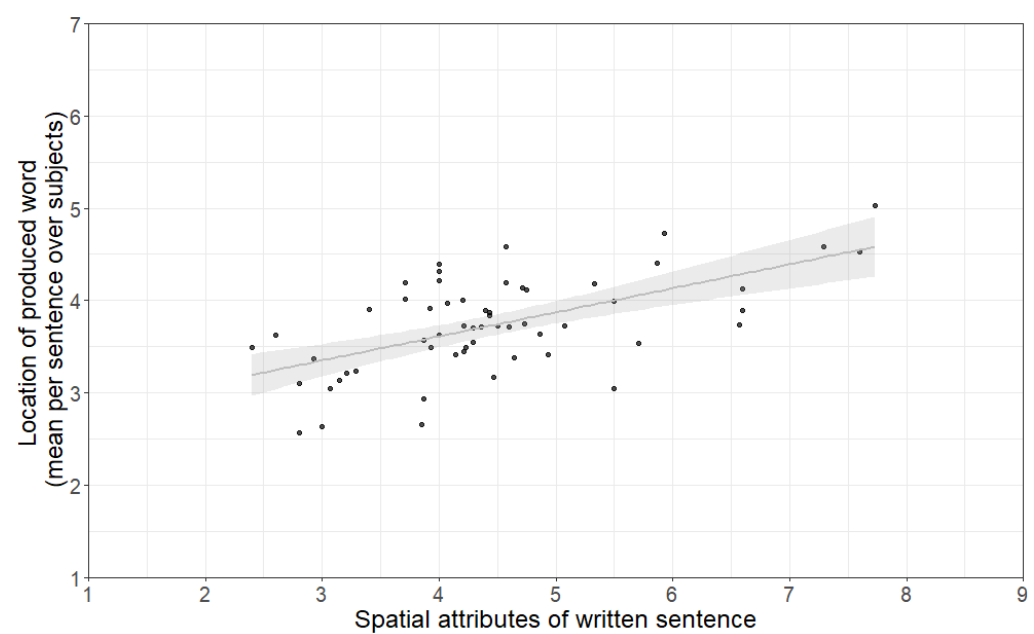

Figure 5. The spatial location of nouns in the sentence fragments predicts the location of the noun referents chosen as suitable sentence endings. The line depicts the effect as estimated in the linear models, the dots represent mean spatial values of the produced words for each sentence fragment respectively. Spatial locations of the entities referred to with the produced nouns were rated on a scale ranging from 1 (down) to 7 (up) after the experiment. Spatial locations of nouns in the sentence were rated on a scale ranging from 1 (down) to 9 (up) before the experiment. For illustrative purposes, sentence noun spatial locations are not centered.

For comparison with Experiment 1, an additional linear model was fitted post hoc to allow for a direct comparison of ascending vs. descending presentation direction. Nouns produced after ascending sentences were located lower in space $\left(M_{u p}=3.64\right)$ than nouns produced after descending sentences $\left(M_{\text {down }}=3.73\right)$, as demonstrated by a significant main effect for the contrast of descending vs. ascending presentation direction in the linear mixed model $\quad(\beta=-0.09[-0.17 ; 0.00], \quad t=-2.01$, $p=.045)$. 
The differential outcomes of Experiment 1 and 2 were further investigated by comparing results from the subset of sentences with overlapping noun use between experiments ( 27 out of 60 sentences). For the subset of sentences from Experiment 2, linear mixed models were specified as above without random intercepts for subjects due to singular fit. This again resulted in a significant difference between ascending and central presentation direction $(\beta=-0.18[-0.32$; $0.04], t=-2.47, p=.014)$, as well as a marginally significant difference between central and descending presentation direction $\quad(\beta=0.14[0.00 ;$

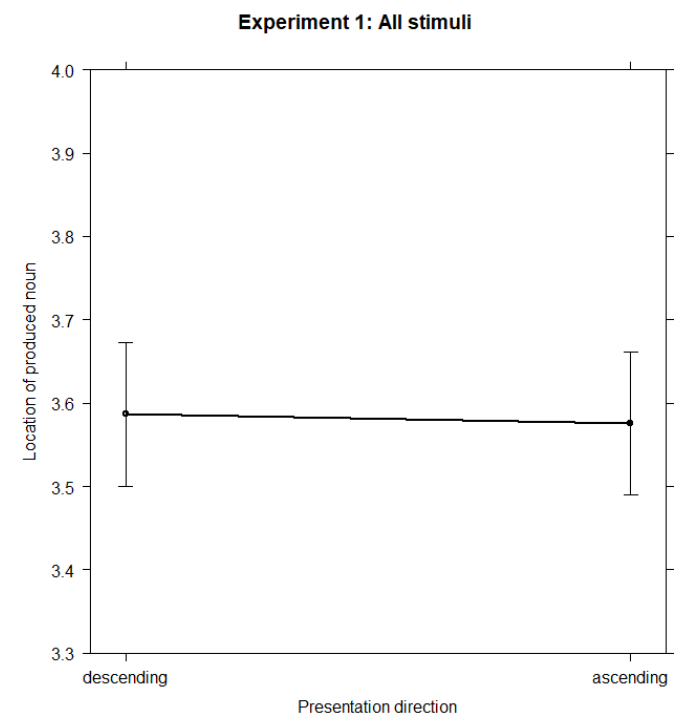

0.28], $t=1.95, p=.051$ ) and a significant effect for sentence spatial location values ( $\beta=0.31[0.16 ; 0.46], t=4.16, p<.001)$. In comparing ascending and descending presentation direction directly, no significant difference between ascending and descending presentation direction was obtained $\quad(\beta=-0.03[-0.18 ; \quad 0.10], t=-$ $0.52, p=.605)$, see Figure 6 . Therefore, the difference between ascending and descending presentation direction when analyzing the complete data set of Experiment 2 seems to hinge on items exclusively used in Experiment 2.

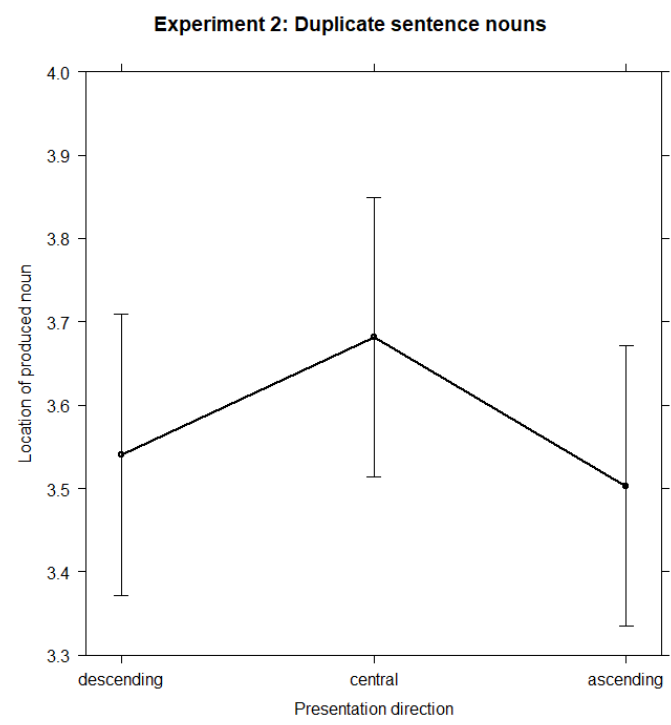

Figure 6. Estimated means of spatial properties of produced nouns depending on the presentation direction of the presented sentences and 95\% confidence intervals. There is no statistical difference between ascending and descending presentation direction in Experiment 1 (left panel) and when investigating the 27 overlapping stimuli from both experiments (right panel).

As in Experiment 1, semantic similarity measures were included in the model to test if the pattern in our data was influenced by the semantic similarity between the content in the displayed sentence and the produced noun. Therefore, cosine values were computed for each pair of nouns (one at the $4^{\text {th }}$ sentence position and the one being produced) in the respective sentence using the semantic space dewak100k_cbow. Cosine values could be computed for 3570 trials out of 3893 which had entered statistical analysis. Centered cosine values were added to the linear model as an additional predictor with a main effect for direction and an interaction between cosine values and 
sentence spatial location values, as well as random intercepts for items and subjects. Again, there was a significant main effect of sentence spatial location $(\beta=0.27[0.18$; $0.36], t=5.79, p<.001)$ as well as a significant difference between central and ascending presentation direction $(\beta=-$ $0.10[-0.18 ;-0.01], \quad t=-2.15, \quad p=.032$ ). Additionally, there was a significant interaction between semantic similarity - as indexed by cosine values - and sentence spatial location values $(\beta=0.54[0.26$; $0.81], t=3.86, p<.001)$, indicating that the effect of sentence spatial characteristics was influenced by the degree of semantic similarity between the sentence noun and the produced noun, see Figure 7. For similar results obtained by using the corpus de_wiki see supplement $\mathbf{S} 2$.

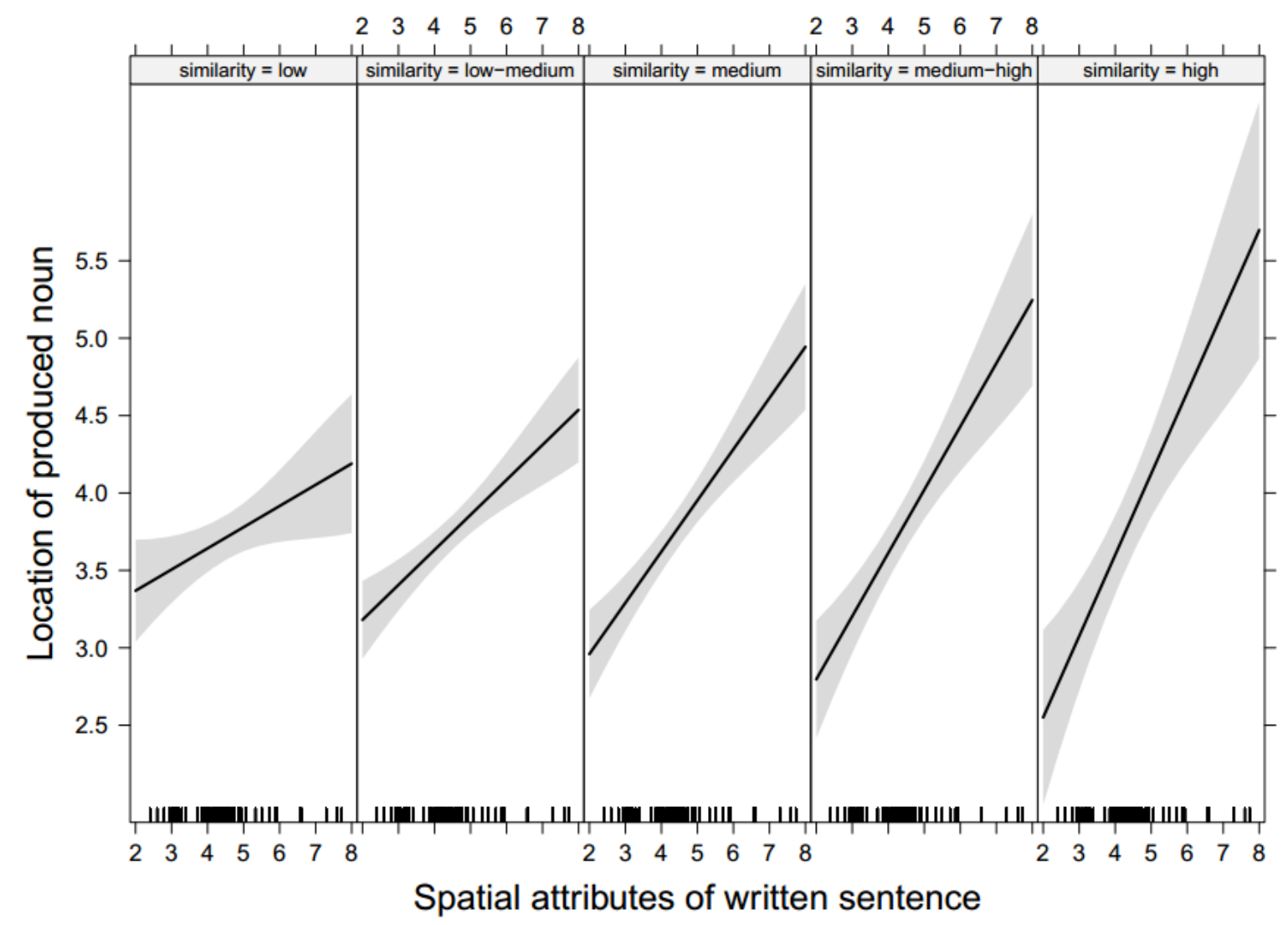

Figure 7. Effect plot showing more pronounced influences of the spatial attributes of the presented sentences on the spatial characteristics of the produced nouns for increasing degrees of semantic similarity between the noun in the presented sentence and the produced noun was more pronounced. Higher values for location of the produced noun - as well as for spatial attributes of the written sentences - indicate a higher localization in space. Small ticks above the x-axis mark the spatial property distribution of the set of sentences. For illustrative purposes, sentence spatial locations are not centered as they were in the analysis. The continuous predictor of similarity was split into five points of equal distance. Low and high similarity refer to the lowest vs. highest cosine values obtained in this study. They are used as descriptive labels, while no pre-defined level of degrees of semantic similarity with regard to cosine values exists. 
We further investigated this interaction by splitting the range of obtained cosine similarities in between the highest and lowest similarity values in equally distant ranges. Then, we explored whether the effect of spatial characteristics of sentences on the produced nouns is contingent on a certain level of semantic similarity or if it exists across the entire range of semantic similarities. ${ }^{\mathrm{V}}$ Taking all trials from each level of similarity (low, low-medium, medium-high, high) into account, separate linear mixed models with the fixed predictors presentation direction, centered spatial location and random intercepts for items - as well as subjects were computed. In case of singular fit, random effect structures were simplified. As shown in Table 1, the effect of spatial characteristics of sentence locations on spatial locations of produced nouns is significant for each level of semantic similarity and gets more pronounced with higher degrees of semantic similarity between sentence nouns and produced nouns. 
Table 1

LMM statistics for the influence of presentation direction and sentence spatial location on the spatial properties of the produced nouns for different degrees of semantic similarity between the sentence noun and the produced noun based on centered cosine values. To illustrate the range of cosine values, the non-centered equivalents of the cosine values on which analyses were based are given together with example pairs from the data set consisting of a noun which had been part of the presented sentence and two exemplars of nouns produced after these sentences.

\begin{tabular}{|c|c|c|c|c|c|c|c|c|c|c|c|c|c|c|c|c|}
\hline Similarity & low & & & & low-m & dium & & & mediu & a-high & & & high & & & \\
\hline Range & $0<\mathrm{co}$ & $\leq 0.216$ & & & 0.216 & $\cos \leq 0.366$ & & & 0.366 & $\cos \leq 0.516$ & & & 0.516 & $\cos$ & & \\
\hline Examples & tree - & ady bug, pictu & & & tree - & icycle, swing & & & tree - & ird, squirrel & & & tree - & ranch, leaves & & \\
\hline & house & - stars, swing & & & house & - fence, chair & & & house & -garage, wind & & & house & - hut, garden & & \\
\hline & lake - & animal, towel & & & lake - & nflatable matt & ess, fish & ing rod & lake - & sier, water lily & & & lake - & boat, shore & & \\
\hline & $\mathrm{n}=85$ & & & & $\mathrm{n}=14$ & & & & $\mathrm{n}=96$ & & & & $\mathrm{n}=29$ & & & \\
\hline & & & & & no ran & lom intercept $\mathrm{f}$ & or subje & & no ran & lom intercepts & for sub & ects & no ran & lom intercepts & for subj & cts \\
\hline Variable & $b$ & $C I$ & $t$ & $p$ & $b$ & $C I$ & $t$ & $p$ & $b$ & $C I$ & $t$ & $p$ & $b$ & $C I$ & $t$ & $p$ \\
\hline Intercept & 3.66 & {$[3.51 ; 3.80]$} & 49.27 & $<.001$ & 3.72 & {$[3.59 ; 3.85]$} & 55.48 & $<.001$ & 3.69 & {$[3.50 ; 3.88]$} & 38.04 & $<.001$ & 3.70 & {$[3.41 ; 3.98]$} & 25.56 & $<.001$ \\
\hline $\begin{array}{l}\text { Direction } \\
\text { (cent-down) }\end{array}$ & -0.14 & {$[-0.33 ; 0.04]$} & -1.51 & .131 & 0.04 & {$[-0.10 ; 0.18]$} & 0.50 & .618 & -0.09 & {$[-0.24 ; 0.05]$} & -1.24 & .214 & 0.04 & {$[-0.17 ; 0.25]$} & 0.35 & 0.726 \\
\hline $\begin{array}{l}\text { Direction } \\
\text { (up-cent) }\end{array}$ & 0.00 & {$[-0.19 ; 0.19]$} & 0.00 & .996 & -0.12 & {$[-0.26 ; 0.02]$} & -1.64 & .102 & -0.12 & {$[-0.26 ; 0.03]$} & -1.58 & .114 & -0.13 & {$[-0.34 ; 0.09]$} & -1.15 & 0.251 \\
\hline $\begin{array}{l}\text { Sentence } \\
\text { Location }\end{array}$ & 0.20 & {$[0.08 ; 0.32]$} & 3.31 & .002 & 0.22 & {$[0.11 ; 0.33]$} & 4.03 & $<.001$ & 0.25 & {$[0.09 ; 0.41]$} & 3.14 & .003 & 0.49 & {$[0.23 ; 0.75]$} & 3.67 & $<.001$ \\
\hline
\end{tabular}


Furthermore, we additionally explored in how far the observed effects of sentence spatial location on lexical choices hinged on predictability. To this end, we computed cloze values for the stimuli which ranged from $0.07-0.43$ per sentence proving that none of the sentence endings was highly predictable. The absolute number of produced words per stimulus sentence ranged from 17-42 different words, see Supplement S3 for information on the predictability of words for each sentence from our stimulus material.

We then ran an additional post-hoc analysis with only those sentences included where less than 36 different nouns had been produced as an answer (in total 72 different nouns could have been produced potentially) which are the more highly predictable stimuli in the stimulus set. This reduced dataset with 40 out of 59 stimulus sentences yielded very similar results to the main analysis with a significant interaction between spatial location of sentences and semantic similarity, $\beta_{\text {high-pred }}=0.57$, $t=3.28, p=.001$.

On the contrary, when looking at those cases where participants had produced the most diverse answers, i.e. 36 or more different nouns per sentence (19 out of 59 stimulus sentences), there was no interaction between spatial locations and semantic similarity,

$\beta_{\text {low-pred }}=0.31, t=1.43, p=.153$ while the main effect for spatial locations of stimulus sentences on spatial locations of produced nouns was significantly evident in both subsets, $\beta_{\text {high-pred }}=0.24, t=3.94, p<.001$ and $\beta_{\text {low-pred }}=0.30, t=6.05, p<.001$. Thus, the effect of spatial locations of the stimulus material on spatial locations of the produced nouns persists when predictability is minimized.

\section{Discussion}

We replicated the main effect of sentence spatial locations, finding that the referents of produced nouns were higher up/lower in the world when sentences described situations higher up/lower in the world, as indicated by prior ratings of the nouns in these written sentences. For example, when choosing suitable sentence endings for the sentence 'You are at the vantage point and you see ...' participants chose words such as 'sky', 'mountains', 'skyscraper' or 'Ferris wheel' while they completed the sentence 'You are at the canal and you see...' with words like 'ant', 'stones' or 'litter'. By showing that spatial meaning traces influence the choice of words in an open language production task we were able to demonstrate that experientially driven meaning aspects in the spatial domain have an impact on lexical selection during language production. Furthermore, there was an interaction between semantic similarity and sentence spatial location, indicating that the effect of sentence spatial location on the spatial properties of the produced noun was higher when the sentence noun and the produced noun were semantically related. In contrast to Experiment 1, there was a significant effect of the spatial manipulation on the spatial properties of the produced nouns. The different results in Experiment 1 and 2 concerning the influence of semantic similarity and the impact of presentation direction on the spatial properties of the produced nouns are discussed in the next section.

\section{General Discussion}

In two experiments we investigated the role of experientially grounded meaning 
in language production. We manipulated the meaning dimension of 'location in space' in two complementary context conditions in one of two ways: (1) physically and isolated from the meaning of verbal contexts as a simulated ascending or descending movement or (2) embedded within verbal contexts. Specifically, participants read sentence fragments like 'You hike through the forest and you see...' and completed them with a suitable noun of their choice. Starting from the center of the screen, the words were presented in a simulated up- or downward movement, i.e. a physical vertical visual manipulation. Additionally, spatial cues were conveyed via the meaning of the sentences, i.e. verbally referring to situations in different spatial locations like 'You walk to the field and you see...' or 'You are on the balcony and you see...' . We tested whether the physically or verbally transmitted spatial experiential manipulations affect our lexical choices.

\section{Experiential traces embedded in meaningful contexts, but not physical cues, lead to experientially grounded lexical selection}

Contrary to the hypothesis that visual motion affects lexical selection, the physical simulation of visual motion did not influence which words participants chose in Experiment 1 and the result was replicated in Experiment 2 when considering the set of sentence nouns which had already been used in Experiment 1. There were no differences in spatial characteristics for nouns produced after descending vs. ascending sentences. The unexpected effect of spatial characteristics of produced nouns being higher after centrally presented sentences than after descending and ascending ones in Experiment 2 seems to be an artifact of this additional condition. The central condition differed from ascending and descending movement manipulations because sentences were presented statically without movement simulations involved. Furthermore, the difference between ascending and descending presentation direction for the whole set of stimuli in Experiment 2 seems to hinge on some of the newly introduced sentence nouns, as it was not existent for the set of items in Experiment1. Additionally, these effects were small compared to the effects of sentence spatial locations on produced nouns (to be discussed in detail below). Therefore, the unexpected effects for Experiment 2 are not reliably observed and may have been caused by the additional central sentence presentation as well as variations in stimulus material. Potentially, in future studies, a sentence display where the control condition is displayed with a slight shift movement to the right - and not statically - might help to clarify this issue. With regards to stimulus material, Experiment 1 and 2 differed as follows: stimulus sentence were presented with article (Exp. 1) but without article (Exp. 2), and the stimulus set in Experiment 2 was more generic with verbs not describing manner of motion as some verbs in Experiment 1 did (in Experiment 2 five different verbs had been used: 'stand', 'walk', 'enter', 'go' and 'be', whereas in Experiment 1 thirty different verbs had been used, among which verbs like 'balance', 'paddle'). Furthermore, the stimulus set was reduced to 60 stimulus sentences in Experiment 2 (Exp. 1: 90 stimulus sentences). We do not have an assumption why these differences may have led to the unexpected effect. The comparison of effects between Experiment 1 and 2 with identical situations described 
in the stimulus sentences (see Figure 6) suggests that not only the central presentation but also some differences in the stimulus material between Experiment 1 and 2 may have contributed to different outcomes. However, this may not generalize and should rather be interpreted as no support for an effect of visual spatial manipulations on lexical selection. New data from an experiment in which we investigated whether body posture changes influence lexical choices and were we used most of the stimuli from Experiment 2 further support this interpretation. In this study, there was a significant difference between nouns produced after upward head movements compared to downward head movements, in line with the hypotheses.

The absence of an effect of physical cues speaks against a high susceptibility for experientially grounded aspects on lexical access during language production. This stands in contrast to empirical evidence for experientially grounded language comprehension where influences of visual cues on processing of sentences, nouns and verbs have been reported in different paradigms (Dudschig et al., 2013; Kaschak et al., 2005; Meteyard et al., 2008). One possible explanation for the lack of comparable effects in language production is that the physical manipulation does not transport sufficient meaning to affect the lexical-semantic construction of verbal messages. Analogously, it has been shown that physical spatial cues alone are not sufficient to facilitate an anagram solving task, whereas the combination of spatial and situational cues are (Berndt et al., 2018). Presumably, a higher task relevance of the physical manipulation leading to more effortful linguistic processing (Louwerse et al., 2015) and / or a stronger bodily involvement (i.e. by changing the body position as in the study by Lachmair et al., 2016,) may yield an effect of spatial manipulations on lexical selection. We explored this question in a follow-up study in which participants listened to similar sentence fragments while producing an upward or downward head movement with eyes being closed and producing suitable sentence endings with heads up vs. down. We replicated the effects of sentence spatial properties on the spatial properties of produced nouns which are the focus of this paper. Additionally, we found an effect of head movement on the locations of produced nouns in this study which we interpret as evidence for the position that a substantial amount of experiential reactivation is needed to have an influence on lexical access (Vogt et al., 2022).

An additional factor which might have contributed to the absence of an effect of visual sentence movement is a lack of variability in spatial location of produced words as most words were rated as rather downward related. Given the data from the head movement study where we also observed that produced words tended to be more downward than upward we do not consider this lack of variability the best explanation for the absence of the expected effect.

In contrast to the purely physical visual stimulation, the spatial context manipulation conveyed by the sentences carried more meaning. Indeed, the produced words were influenced by the spatial characteristics of the presented sentence fragments. For example, after reading a sentence like 'You are at the sea and you see...' participants were more likely to say 'a shell' than 'a gull'. Crucially, both shells and gulls can be found at the sea. Furthermore, both words get assigned a comparable semantic 
similarity when using distributional measures of semantics as we did in our study (sea-shell: 0.40; sea-gull: 0.41; on a scale from 0 (no similarity) to 1 (synonyms). However, words additionally sharing the spatial location with the situation described by the sentences were more likely to be selected.

We take this as evidence that experiential knowledge not only affects the way word meaning is represented, but also that it is activated during lexical-semantic planning stages, thereby influencing which words we choose. It has been shown by Ostarek and Vigliocco (2017) that identification of pictorial stimuli was facilitated when presented $250 \mathrm{~ms}$ after reading words which belong to the same event (e.g. reading 'sky' and seeing 'cloud') when the image was presented in the same vertical location where it is typically seen which demonstrates the importance of events during perceptual simulation. Therefore, we deem it likely that in our experiments participants simulate the scenes described by the sentences and that these simulations modulate conceptual and lexical processing. According to situation model theory, specifically the event-indexing model (Zwaan \& Radvansky, 1998), space is an important meaning dimension when it comes to integrating different pieces of information given in the linguistic input. From this perspective, it is not surprising that participants produced words that share the spatial properties of the simulations they created when reading the previous linguistic input. In general, it seems that situation model theory (e.g. Zwaan, 2016) fits well with our results, assuming a division of labor between more symbolic and more grounded representations in discourse and thus providing a good explanation for the combined effects of semantic similarity and the more experientially grounded meaning dimension observed in the present study.

To summarize, while many other factors - regarding the selected content words - may play a role during the lexical selection process, we want to highlight that experientially grounded meaning seems to be one important factor in language production. Also, we would like to point out that our results fit well with situation model theory.

\section{The relation between experientially grounded meaning and predictability}

It might be argued that the produced words are all more or less predictable given the sentential context in the sense that most of them would probably not lead to processing difficulties when presented in a comprehension task and that it is therefore important to clarify whether the observed effect is carried by spatial location specifically or more generally by predictability. However, even when only examining the stimuli where participants showed most variability in answering, i.e. at least on average every second participant produced a different word, we still obtained the main effect that spatial locations of the stimulus material predicted the spatial properties of the produced nouns.

We think that the notion of predictability with regards to lexical selection is empirically underspecified so far and that more research should be done to investigate which factors contribute to words being predicted in a given context. Our data show that experientially grounded meaning facets might be among those factors. Additionally, statistical distributional properties of language might be important for predictability. 


\section{The relation between experientially grounded meaning and traditional semantic measures}

The

experience-related

manipulation of space employed here is embedded in meaningful contexts, but at the same time distinct from semantic context measures known to affect lexicalsemantic processing during language production, such as semantic features, associations, thematic relations or categories (Abdel Rahman \& Melinger, 2019; McRae, Cree, Seidenberg, \& McNorgan, 2005). To further examine the influence of the semantic contents of the presented sentences on the produced nouns we included a distributional semantic similarity measure as a covariate in our analysis. We used cosine values computed from text corpora as they are an established measure in the field of semantics and therefore they provided a pragmatic way to yield similarity values for the large data set at hand. As the estimates of semantic similarity are based on huge language corpora they pick up on the statistical linguistic regularities which we encounter in our daily life and are therefore very strong tools in modeling our linguistic behavior. Even though distributional measures of semantics have hardly been incorporated into research on semantic processing in language production (Vinson et al., 2014) they are in our view perfectly suited for quantifying the semantic relationship between the nouns in the sentence fragments and the produced nouns. In Experiment 2 we found a more pronounced effect of spatial characteristics of the presented sentence on the spatial properties of the produced nouns for semantically related relative to unrelated pairs. More precisely, the closer the produced noun was to the content in the visually presented sentence, the stronger the impact of spatial location of the presented sentence fragment on the spatial location of the produced noun. Note that this interaction between similarity and sentence spatial location was only apparent in Experiment 2. This suggests that the presented article in the first experiment made it more difficult for the semantically most associated nouns to be produced. Indeed, the mean cosine value across all trials was lower in Experiment 1 (mean cosine value: 0.21 ) than in Experiment 2 (mean cosine value: 0.32 ), that is, produced nouns were overall less semantically related to the content of sentences in Experiment 1 than in Experiment 2. Thus, the design of Experiment 1, in which a determiner restricted the range of possible nouns, made it less likely that the produced nouns were chosen merely because their semantic association to the sentence context was strongest.

Crucially, however, we found that the spatial location values of the sentence nouns predicted the spatial properties of the produced nouns in Experiment 1. Moreover, in Experiment 2, the effect of sentence spatial location on spatial characteristics of the produced nouns was still existent in cases of minimal and high similarity relation. That is, even among the most loosely related cases, nouns were chosen which shared the spatial dimension on top. Therefore, the semantic similarity measure used here cannot entirely explain the relationship between the spatial characteristics of the sentence material and the produced nouns. Rather, similarity seems to work as a moderator, influencing the strength of the impact of spatial properties of the stimuli on the dependent variable. We conclude that meaning aspects as captured by the similarity measure and 
experientially grounded sensory meaning are closely entangled, but distinguishable, in line with theoretical accounts (Louwerse, 2018; Vigliocco et al., 2009).

Similar results have recently been obtained by Banks et al. (2021). Using a category production task, they were able to predict performance when taking both shared sensorimotor knowledge and linguistic proximity based on distributional knowledge into account. This goes in line with our interpretation that experiential and linguistic associations are both important, contributing separately to the responses we found.

\section{Conclusions}

In the present study, we show that lexical-semantic processes during language production are not influenced by physical spatial cues isolated from meaning. Instead, we provide evidence that lexical choices are influenced by experientially grounded sensory meaning of space - as conveyed by the verbal context - and that these choices are modulated by distributional properties of the linguistic context. This is in line with current hybrid theories of semantic memory, which treat sensorimotor aspects and usage-based distributional aspects of language as separate - but interacting types of meaning (Carota et al., 2021; Davis \& Yee, 2021; Vigliocco et al., 2009).

We propose that message planning for speaking does not only involve classic semantic meaning relations as categorical or associative links but may also include other aspects of meaning grounded in sensory, motor or bodily experiences. Future research should study whether the impact of the meaning dimension of 'location in space' is captured best as a reactivation of sensorimotor experiences, and thus constitutes evidence for experiential grounding in language production, or whether spatial locations are activated as part of propositional and amodal semantic features (Meteyard et al., 2012). However, based on the evidence reviewed in the Introduction and evidence for activation of spatial-oculomotor regions in the brain during the processing of implicitly spatial nouns (Ostarek, 2018) we deem the meaning aspect of 'locations in space' a strong candidate for experientially grounded meaning.

In the experimental task employed here we investigated which words are chosen during lexical-semantic processing. Traditionally, most studies dealing with lexical access in language production manipulate the context of an utterance, whereas the to-be-produced word is predetermined by the experimental setup (various picture naming tasks, e.g., cyclic blocking, picture-word interference, continuous naming). Production tasks with a focus on semantics rarely allow for free lexical choices even though recent studies have moved in this direction (e.g. Fjaellingsdal et al., 2020). Here, participants were not entirely unrestricted in their lexical choices, but could freely select their utterances within nonconstraining contexts, allowing us to investigate which factors shape the content of a produced message, rather than the duration of lexical processing. As is typical in everyday language use, our task also encompassed an interplay of comprehension and production (Indefrey \& Levelt, 2004; Pickering \& Garrod, 2013). Therefore, our experiments provide an important step towards a more complete understanding of one of the crucial elements of language production and we hope to spark interesting discussions and studies which will shed more light on the 
factors which contribute to answering the question why we choose certain words in order to express an intended meaning.

\section{References}

Abdel Rahman, R., \& Melinger, A. (2007). When bees hamper the production of honey: lexical interference from associates in speech production. Journal of Experimental Psychology: Learning, Memory, and Cognition, 33(3), 604-614. https://doi.org/10.1037/02787393.33.3.604

Abdel Rahman, R., \& Melinger, A. (2019). Semantic processing during language production: an update of the swinging lexical network. Language, Cognition and Neuroscience, 34(9), 1176-1192. https://doi.org/https://doi.org/10.1080 /23273798.2019.1599970

Alario, F. X., Segui, J., \& Ferrand, L. (2000). Semantic and associative priming in picture naming. The Quarterly Journal of Experimental Psychology Section A, 53(3), 741-764. https://doi.org/10.1080/713755907

Andrews, M., Frank, S., \& Vigliocco, G. (2014). Reconciling embodied and distributional accounts of meaning in language. Topics in Cognitive Science, $6(3)$, 359-370. https://doi.org/10.1111/tops.12096

Aravena, P., Courson, M., Frak, V., Cheylus, A., Paulignan, Y., Deprez, V., \& Nazir, T. A. (2014). Action relevance in linguistic context drives word-induced motor activity. Frontiers in Human Neuroscience, 8 , Article 163. https://doi.org/10.3389/fnhum.2014.0

\section{3}

Aristei, S., \& Abdel Rahman, R. (2013). Semantic interference in language production is due to graded similarity, not response relevance. Acta Psychologica, 144(3), 571-582. https://doi.org/10.1016/j.actpsy.2013. 09.006

Banks, B., Wingfield, C., \& Connell, L. (2021). Linguistic distributional knowledge and sensorimotor grounding both contribute to semantic category production. Cognitive Science, 45(10), Article e13055. https://doi.org/10.1111/cogs.13055

Baroni, M., Bernardini, S., Ferraresi, A., \& Zanchetta, E. (2009). The waCky wide web: A collection of very large linguistically processed web-crawled corpora. Language Resources and Evaluation, 43(3), 209-226. https://doi.org/10.1007/s10579-0099081-4

Barsalou, L. W. (1999). Perceptual symbol systems. Behavioral and Brain Sciences, 22(4), 577-660. https://doi.org/10.1017/S0140525X99 002149

Barsalou, L. W. (2008). Grounded cognition. Annual Review of Psychology, 59, 617-645. https://doi.org/10.1146/annurev.psych .59 .103006 .093639

Bates, D., Mächler, M., Bolker, B., \& Walker, S. (2015). Fitting linear mixed-effects models using lme4. Journal of Statistical Software, 67(1), $1-48$. https://doi.org/10.18637/jss.v067.i01

Belke, E., Meyer, A. S., \& Damian, M. F. (2005). Refractory effects in picture naming as assessed in a semantic blocking paradigm. The Quarterly Journal of Experimental Psychology 
Section A, 58(4), 667-692. https://doi.org/10.1080/02724980443 000142

Ben-Haim, M. S., Chajut, E., Hassin, R. R., \& Algom, D. (2015). Speeded naming or naming speed? The automatic effect of object speed on performance. Journal of Experimental Psychology: General, 144(2), 326-338. https://doi.org/10.1037/a0038569

Bergen, B. K. (2015). Embodiment. In E. Dabrowska \& D. Divjak (Eds.), Handbook of Cognitive Linguistics (pp. 10-30). De Gruyter Mouton.

Bergen, B. K., Lindsay, S., Matlock, T., \& Narayanan, S. (2007). Spatial and linguistic aspects of visual imagery in sentence comprehension. Cognitive Science, 31(5), 733-764. https://doi.org/10.1080/03640210701 530748

Berndt, E., Dudschig, C., \& Kaup, B. (2018). Activating concepts by activating experiential traces: investigations with a series of anagram solution tasks. The Quarterly Journal of Experimental Psychology, 71(2), 483-498.

https://doi.org/10.1080/17470218.201 6.1261913

Binder, J. R., \& Desai, R. H. (2011). The neurobiology of semantic memory. Trends in Cognitive Sciences, 15(11), 527-536.

https://doi.org/10.1016/j.tics.2011.10. 001.

Block, C. K., \& Baldwin, C. L. (2010). Cloze probability and completion norms for 498 sentences: Behavioral and neural validation using eventrelated potentials. Behavior Research Methods, 42(3), 665-670. https://doi.org/10.3758/BRM.42.3.66 5
Bürki, A., Elbuy, S., Madec, S., \& Vasishth, S. (2020). What did we learn from forty years of research on semantic interference? A Bayesian metaanalysis. Journal of Memory and Language, 114, Article 104125. https://doi.org/https://doi.org/10.1016 /j.jml.2020.104125

Caramazza, A. (1997). How many levels of processing are there in lexical access? Cognitive Neuropsychology, 14(1), 177-208.

https://doi.org/10.1080/02643299738 1664

Carota, F., Nili, H., Pulvermüller, F., \& Kriegeskorte, N. (2021). Distinct fronto-temporal substrates of distributional and taxonomic similarity among words: evidence from RSA of BOLD signals. NeuroImage, 224, Article 117408. https://doi.org/10.1016/j.neuroimage. 2020.117408

Cicchetti, D. V., Shoinralter, D., \& Tyrer, P. J. (1985). The effect of number of rating scale categories on levels of interrater reliability: A Monte Carlo investigation. Applied Psychological Measurement, 9(1), 31-36. https://doi.org/10.1177/01466216850 0900103

Costa, A., Alario, F.-X., \& Caramazza, A. (2005). On the categorical nature of the semantic interference effect in the picture-word interference paradigm. Psychonomic Bulletin \& Review, 12(1), 125-131. https://doi.org/10.3758/BF03196357

Damian, M. F., \& Spalek, K. (2014). Processing different kinds of semantic relations in picture-word interference with non-masked and masked distractors. Frontiers in Psychology, 5, Article

1183. 
https://doi.org/10.3389/fpsyg.2014.01 183

Davis, C. P., \& Yee, E. (2021). Building semantic memory from embodied and distributional language experience. WIREs Cognitive Science, 12(5), Article e1555. https://doi.org/10.31234/OSF.IO/WY MR9

de Zubicaray, G., Fraser, D., Ramajoo, K., \& McMahon, K. (2017). Interference from related actions in spoken word production: Behavioural and fMRI evidence. Neuropsychologia, 96, 7888.

https://doi.org/10.1016/j.neuropsycho logia.2017.01.010

de Zubicaray, G., Hansen, S., \& McMahon, K. (2013). Differential processing of thematic and categorical conceptual relations in spoken word production. Journal of Experimental Psychology: General, 142(1), 131-142. https://doi.org/10.1037/a0028717

de Zubicaray, G., McLean, M., Oppermann, F., Hegarty, A., McMahon, K., \& Jescheniak, J. D. (2018). The shape of things to come in speech production: Visual form interference during lexical access. Quarterly Journal of Experimental Psychology, 71(9), 1921-1938.

https://doi.org/10.1080/17470218.201 7.1367018

Dell, G. S. (1986). A spreading-activation theory of retrieval in sentence production. Psychological Review, 93(3), 283-321. https://doi.org/10.1037/0033-

295X.93.3.283

Díez-Álamo, A. M., Diéz, E., Wojcik, D. Z., Alonso, M. A., \& Fernandez, A. (2018). Sensory experience ratings for 5,500 Spanish words. Behavior
Research Methods, 51(3), 1205-1215. https://doi.org/https://doi.org/10.3758 /s13428-018-1057-0

Dudschig, C., Lachmair, M., de la Vega, I., De Filippis, M., \& Kaup, B. (2012). From top to bottom: spatial shifts of attention caused by linguistic stimuli. Cognitive Processing, 13(Suppl. 1), 151-154.

https://doi.org/10.1007/s10339-0120480-x

Dudschig, C., Souman, J., \& Kaup, B. (2013). Motion in vision and language: seeing visual motion can influence processing of motion verbs. In M. Knauff, M. Pauen, N. Sebanz, \& I. Wachsmuth (Eds.), Proceedings of the 35th Annual Conference of the Cognitive Science Society (pp. 22252230). Cognitive Science Society.

Durda, K., Buchanan, L., \& Caron, R. (2009). Grounding co-occurrence: Identifying features in a lexical cooccurrence model of semantic memory. Behavior Research Methods, 41(4), 1210-1223. https://doi.org/10.3758/BRM.41.4.12 10

Estes, Z., Verges, M., \& Barsalou, L. W. (2008). Head up, foot down: object words orient attention to the objects' typical location. Psychological Science, 19(2), 93-97. https://doi.org/10.1111/j.14679280.2008.02051.x.

Fargier, R., Montant, M., \& Strijkers, K. (2019). The activation of sensory and emotional experience during speech production. Poster Presented at the Meeting of the French Society of Neuroscience.

Finn, R. H. (1972). Effects of some variations in rating scale characteristics on the means and 
reliabilities of ratings. Educational and Psychological Measurement, 32(2), 255-265. https://doi.org/10.1177/00131644720 3200203

Firth, J. R. (1957). A synopsis of linguistic theory, 1930-55. In Studies in linguistic analysis (pp. 1-32). Blackwell.

Fjaellingsdal, T. G., Schwenke, D., Scherbaum, S., Kuhlen, A. K., Bögels, S., Meekes, J., \& Bleichner, M. G. (2020). Expectancy effects in the EEG during joint and spontaneous word-byword sentence production in German. Scientific Reports, 10, Article 5460. https://doi.org/10.1101/782581

Fleiss, J. L. (1986). The design and analysis of clinical experiments. Wiley. https://doi.org/10.1002/bimj.4710300 308

García, A. M., Moguilner, S., Torquati, K., García-Marco, E., Herrera, E., Muñoz, E., Castillo, E. M., Kleineschay, T., Sedeño, L., \& Ibáñez, A. (2019). How meaning unfolds in neural time: Embodied reactivations can precede multimodal semantic effects during language processing. NeuroImage, 197, 439-449. https://doi.org/10.1016/j.neuroimage. 2019.05.002

Glaser, W. R., \& Düngelhoff, F.-J. (1984). The time course of picture-word interference. Journal of Experimental Psychology: Human Perception and Performance, 10(5), 640-654. https://doi.org/10.1037//00961523.10.5.640.

Günther, F., Dudschig, C., \& Kaup, B. (2015). LSAfun - An R package for computations based on Latent Semantic Analysis. Behavior Research Methods, 47(4), 930-944. https://doi.org/10.3758/s13428-0140529-0

Günther, F., Dudschig, C., \& Kaup, B. (2018). Symbol grounding without direct experience: Do words inherit sensorimotor activation from purely linguistic context? Cognitive Science, 42(Suppl 2), 336-374. https://doi.org/10.1111/cogs.12549

Günther, F., Nguyen, T., Chen, L., Dudschig, C., Kaup, B., \& Glenberg, A. M. (2020). Immediate sensorimotor grounding of novel concepts learned from language alone. Journal of Memory and Language, 115, Article 104172. https://doi.org/10.1016/j.jml.2020.10 4172

Günther, F., Rinaldi, L., \& Marelli, M. (2019). Vector-space models of semantic representation from a cognitive perspective: a discussion of common misconceptions. Perspectives on Psychological Science, 14(6), 1006-1033. https://doi.org/10.1177/17456916198 61372

Hallgren, K. A. (2012). Computing interrater reliability for observational data: An overview and tutorial. Tutorials in Quantitative Methods for Psychology, $8(1)$, 23-34. https://doi.org/10.20982/tqmp.08.1.p0 23.

Harnad, S. (1990). The symbol grounding problem. Physica D, 42, 335-346.

Herrera, E., Rodríguez-Ferreiro, J., \& Cuetos, F. (2012). The effect of motion content in action naming by Parkinson's disease patients. Cortex, 48(7), 900-904. https://doi.org/10.1016/J.CORTEX.2 010.12.007

Hirschfeld, G., \& Zwitserlood, P. (2012). 
Effector-specific motor activation modulates verb production. Neuroscience Letters, 523(1), 15-18. https://doi.org/10.1016/j.neulet.2012. 06.025

Hoenig, K., Sim, E.-J., Bochev, V., Herrnberger, B., \& Kiefer, M. (2008). Conceptual flexibility in the human brain: dynamic recruitment of semantic maps from visual, motor, and motion-related areas. Journal of Cognitive Neuroscience, 20(10), 1799-1814.

https://doi.org/10.1162/jocn.2008.201 23

Howard, D., Nickels, L., Coltheart, M., \& Cole-Virtue, J. (2006). Cumulative semantic inhibition in picture naming: experimental and computational studies. Cognition, 100(3), 464-482. https://doi.org/10.1016/J.COGNITIO N.2005.02.006

Hustá, C., Zheng, X., Papoutsi, C., \& Piai, V. (2021). Electrophysiological signatures of conceptual and lexical retrieval from semantic memory. Neuropsychologia, 161, 107988. https://doi.org/10.1016/j.neuropsycho logia.2021.107988

Indefrey, P., \& Levelt, W. J. M. (2004). The spatial and temporal signatures of word production components. Cognition, 92(1-2), 101-144. https://doi.org/10.1016/j.cognition.20 02.06.001

Jackson, R. L., Hoffman, P., Pobric, G., \& Lambon Ralph, M. A. (2015). The nature and neural correlates of semantic association versus conceptual similarity. Cerebral Cortex, 25(11), 4319-4333. https://doi.org/10.1093/cercor/bhv003 Kaschak, M. P., Madden, C. J., Therriault, D. J., Yaxley, R., Aveyard, M.,
Blanchard, A. A., \& Zwaan, R. A. (2005). Perception of motion affects language processing. Cognition, 94(3), B79-B80.

https://doi.org/10.1207/s15516709cog 0000_54

Kaup, B., de la Vega, I., Strozyk, J., \& Dudschig, C. (2015). The role of sensorimotor processes in meaning composition. In M. H. Fischer \& Y. Coello (Eds.), Conceptual and Interactive Embodiment: Foundations of Embodied Cognition Volume 2 (Vol. 2, pp. 46-66). Routledge. https://doi.org/10.4324/97813157519 62

Kiefer, M., \& Pulvermüller, F. (2012). Conceptual representations in mind and brain: theoretical developments, current evidence and future directions. Cortex, 48(7), 805-825. https://doi.org/10.1016/j.cortex.2011. 04.006

Kuznetsova, A., Brockhoff, P. B., \& Christensen, R. H. B. (2017). lmerTest package: tests in linear mixed effects models. Journal of Statistical Software, $\quad 82(13), \quad$ 1-26. https://doi.org/10.18637/jss.v082.i13

La Heij, W., Dirkx, J., \& Kramer, P. (1990). Categorical interference and associative priming in picture naming. British Journal of Psychology, 81(4), 511-525.

https://doi.org/10.1111/j.20448295.1990.tb02376.x

Lachmair, M., Dudschig, C., De Filippis, M., de la Vega, I., \& Kaup, B. (2011). Root versus roof: automatic activation of location information during word processing. Psychonomic Bulletin \& Review, 18(6), 1180-1188. https://doi.org/10.3758/s13423-0110158-x 
Lachmair, M., Dudschig, C., de la Vega, I., \& Kaup, B. (2016). Constructing meaning for up and down situated sentences: Is a sentence more than the sum of its words? Language and Cognition, 8(4), 604-628. https://doi.org/10.1017/langcog.2015. 11

Lachmair, M., Ruiz Fernández, S., Bury, N.-A., Gerjets, P., Fischer, M. H., \& Bock, O. L. (2016). How body orientation affects concepts of space, time and valence: functional relevance of integrating sensorimotor experiences during word processing. PLoS ONE, 11(11), Article e0165795. https://doi.org/10.1371/journal.pone.0 165795

Lachmair, M., Ruiz Fernández, S., \& Gerjets, P. (2016). Priming effects between spatial meaning of verbs and numbers are modulated by time intervals: Early interference and late facilitation. Canadian Journal of Experimental Psychology, 70(4), 295300.

https://doi.org/10.1037/cep0000085

Levelt, W. J. M., Roelofs, A., \& Meyer, A. S. (1999). A theory of lexical access in speech production. Behavioral and Brain Sciences, 22, 1-75.

Lin, H.-P., Kuhlen, A. K., \& Abdel Rahman, R. (2021). Ad-hoc thematic relations form through communication: effects on lexical-semantic processing during language production. Language, Cognition and Neuroscience, 36(9), 1057-1075.

https://doi.org/10.1080/23273798.202 1.1900580

Louwerse, M. M. (2011). Symbol interdependency in symbolic and embodied cognition. Topics in Cognitive Science, 3(2), 273-302. https://doi.org/10.1111/j.17568765.2010.01106.x

Louwerse, M. M. (2018). Knowing the meaning of a word by the linguistic and perceptual company it keeps. Topics in Cognitive Science, 10(3), 573-589.

https://doi.org/10.1111/tops.12349

Louwerse, M. M., Hutchinson, S., Tillman, R., \& Recchia, G. (2015). Effect size matters: the role of language statistics and perceptual simulation in conceptual processing. Language, Cognition and Neuroscience, 30(4), 430-447.

https://doi.org/10.1080/23273798.201 4.981552

Lynott, D., Connell, L., Brysbaert, M., Brand, J., \& Carney, J. (2020). The Lancaster sensorimotor norms: multidimensional measures of perceptual and action strength for 40,000 English words. Behavior Research Methods, 52(3), 1271-1291. https://doi.org/10.3758/s13428-01901316-Z

Mädebach, A., Kieseler, M. L., \& Jescheniak, J. D. (2018). Localizing semantic interference from distractor sounds in picture naming: a dual-task study. Psychonomic Bulletin \& Review, 25(5), 1909-1916. https://doi.org/10.3758/s13423-0171386-5

Mahon, B. Z., Costa, A., Peterson, R., Vargas, K. A., \& Caramazza, A. (2007). Lexical selection is not by competition: a reinterpretation of semantic interference and facilitation effects in the picture-word interference paradigm. Journal of Experimental Psychology: Learning, Memory, and Cognition, 33(3), 503535. https://doi.org/10.1037/0278- 
7393.33.3.503

Matheson, H. E., White, N., \& McMullen, P. A. (2014). Testing the embodied account of object naming: A concurrent motor task affects naming artifacts and animals. Acta Psychologica, 145(1), 33-43. https://doi.org/10.1016/j.actpsy.2013. 10.012

McRae, K., Cree, G. S., Seidenberg, M. S., \& McNorgan, C. (2005). Semantic feature production norms for a large set of living and nonliving things. Behavior Research Methods, 37, 547559.

Meteyard, L., Cuadrado Rodriguez, S., Bahrami, B., \& Vigliocco, G. (2012). Coming of age: a review of embodiment and the neuroscience of semantics. Cortex, 48, 788-804. https://doi.org/10.1016/j.cortex.2010. 11.002

Meteyard, L., Zokaei, N., Bahrami, B., \& Vigliocco, G. (2008). Visual motion interferes with lexical decision on motion words. Current Biology, 18(17), 732-733. https://doi.org/10.1016/j.cub.2008.07. 016

Mikolov, T., Chen, K., Corrado, G., \& Dean, J. (2013). Efficient Estimation of Word Representations in Vector Space.

https://arxiv.org/abs/1301.3781v3

Mulatti, C., Treccani, B., \& Job, R. (2014). The role of the sound of objects in object identification: evidence from picture naming. Frontiers in Psychology, 5, Article 1139. https://doi.org/10.3389/fpsyg.2014.01 139

Oaster, T. R. F. (1989). Number of alternatives per choice point and stability of Likert-type scales.
Perceptual and Motor Skills, 68(2), 549-550.

https://doi.org/10.2466/pms.1989.68. 2.549

Oppenheim, G. M., Dell, G. S., \& Schwartz, M. F. (2010). The dark side of incremental learning: a model of cumulative semantic interference during lexical access in speech production. Cognition, 114(2), 227252.

https://doi.org/10.1016/j.cognition.20 09.09.007

Ostarek, M. (2018). Envisioning language An exploration of perceptual processes in language comprehension. Radboud Universiteit Nijmegen.

Ostarek, M., \& Huettig, F. (2019). Six challenges for embodiment research. Current Directions in Psychological Science, 28(6), 593-599. https://doi.org/10.1177/09637214198 66441

Ostarek, M., Ishag, A., Joosen, D., \& Huettig, F. (2018). Saccade trajectories reveal dynamic interactions of semantic and spatial information during the processing of implicitly spatial words. Journal of Experimental Psychology: Learning, Memory and Cognition, 44(10), 16581670.

https://doi.org/10.1037/xlm0000536

Ostarek, M., \& Vigliocco, G. (2017). Reading sky and seeing a cloud: on the relevance of events for perceptual simulation. Journal of Experimental Psychology: Learning Memory and Cognition, 43(4), 579-590. https://doi.org/10.1037/xlm0000318

Öttl, B., Dudschig, C., \& Kaup, B. (2017). Forming associations between language and sensorimotor traces during novel word learning. Language 
and Cognition, 9(1), 156-171. https://doi.org/10.1017/langcog.2016. 5

Pecher, D., \& Zwaan, R. A. (2005). Grounding cognition. The role of perception and action in memory, language, and thinking (Vol. 26, Issue 11). Cambridge University Press. https://doi.org/10.1016/j.patrec.2005. 01.006

Pickering, M. J., \& Garrod, S. (2013). An integrated theory of language production and comprehension. Behavioral and Brain Sciences, 36(4), 329-347.

https://doi.org/10.1017/S0140525X12 001495

Pobric, G., Jefferies, E., \& Lambon Ralph, M. A. (2010). Induction of semantic impairments using rTMS: evidence for the hub-and-spoke semantic theory. Behavioural Neurology, 23(4), 217219. https://doi.org/10.3233/BEN2010-0299

Pulvermüller, F. (2018). Neural reuse of action perception circuits for language, concepts and communication. Progress in Neurobiology, 160, 1-44. https://doi.org/10.1016/j.pneurobio.20 17.07.001

Pulvermüller, F., Shtyrov, Y., \& Hauk, O. (2009). Understanding in an instant: neurophysiological evidence for mechanistic language circuits in the brain. Brain and Language, 110(2), 81-94.

https://doi.org/10.1016/J.BANDL.200 8.12.001

R Core Team. (2017). R: A Language and Environment for Statistical Computing. https://www.rproject.org/

Ramsay, J. O. (1973). The effect of number of categories in rating scales on precision of estimation of scale values. Psychometrika, 38(4), 513-532. https://doi.org/10.1007/BF02291492

Redmann, A., FitzPatrick, I., Hellwig, F., \& Indefrey, P. (2014). The use of conceptual components in language production: an ERP study. Frontiers in Psychology, 5, Article 363. https://doi.org/10.3389/fpsyg.2014.00 363

Revelle, W. (2018). psych: Procedures for Psychological, Psychometric, and Personality Research. https://cran.rproject.org/package $=$ psych

Roelofs, A. (2018). A unified computational account of cumulative semantic, semantic blocking, and semantic distractor effects in picture naming. Cognition, 172, 59-72. https://doi.org/10.1016/j.cognition.20 17.12.007

Rose, S. B., \& Abdel Rahman, R. (2016). Cumulative semantic interference for associative relations in language production. Cognition, 152, 20-31. https://doi.org/10.1016/j.cognition.20 16.03.013

Sahlgren, M. (2008). The distributional hypothesis. Italian Journal of Linguistics, 20(1), 33-53.

Scott, G. G., Keitel, A., Becirspahic, M., Yao, B., \& Sereno, S. C. (2019). The Glasgow norms: ratings of 5,500 words on nine scales. Behavior Research Methods, 51(3), 1258-1270. https://doi.org/10.3758/s13428-0181099-3

Searle, J. R. (1980). Minds, brains, and programs. Behavioral and Brain Sciences, 3(3), 417-457. https://doi.org/10.1017/S0140525X00 005756

Sixtus, E., Lindemann, O., \& Fischer, M. H. (2018). Incidental counting: speeded 
number naming through finger movements. Journal of Cognition, 1(1), Article 44. https://doi.org/10.5334/joc.49

Thornton, T., Loetscher, T., Yates, M. J., \& Nicholls, M. E. R. (2013). The highs and lows of the interaction between word meaning and space. Journal of Experimental Psychology: Human Perception and Performance, 39(4), 964-973.

https://doi.org/10.1037/a0030467

Trevethan, R. (2017). Intraclass correlation coefficients: clearing the air, extending some cautions, and making some requests. Health Services and Outcomes Research Methodology, 17(2), 127-143. https://doi.org/10.1007/s10742-0160156-6

Vigliocco, G., Meteyard, L., Andrews, M., \& Kousta, S. (2009). Toward a theory of semantic representation. Language and Cognition, 1(2), 219-247. https://doi.org/10.1515/langcog.2009. 011

Vigliocco, G., Vinson, D. P., Damian, M. F., \& Levelt, W. (2002). Semantic distance effects on object and action naming. Cognition, 85(3), 61-69. https://doi.org/10.1016/S00100277(02)00107-5

Vincent-Lamarre, P., Massé, A. B., Lopes, M., Lord, M., Marcotte, O., \& Harnad, S. (2015). The latent structure of dictionaries. Topics in Cognitive Science, 8(3), 625-659.

Vinson, D. P., Andrews, M., \& Vigliocco, G. (2014). Giving words meaning: why better models of semantics are needed in language production research. In M. Goldrick, V. S. F. Ferreira, \& M. Miozzo (Eds.), The Oxford Handbook of Language
Production (pp. 134-151). Oxford University Press.

Vogt, A., Ganter, I., Kaup, B., \& Abdel Rahman, R. (2022). How body movements can influence which words we choose when speaking: interoceptive sensibility as a moderator in an open language production task. Manuscript in Preparation.

Vogt, A., Kaup, B., \& Dudschig, C. (2019). When words are upside down: language-space associations in children and adults. Journal of Experimental Child Psychology, 186, 142-158.

https://doi.org/10.1016/j.jecp.2019.06 .001

Wingfield, C., \& Connell, L. (2019). Understanding the role of linguistic distributional knowledge in cognition. Psyarxiv.

https://doi.org/10.31234/osf.io/hpm4z

Witt, J. K., Kemmerer, D., Linkenauger, S. A., \& Culham, J. (2010). A functional role for motor simulation in identifying tools. Psychological Science, 21(9), 1215-1219. https://doi.org/10.1177/09567976103 78307

Yee, E., Chrysikou, E. G., Hoffman, E., \& Thompson-Schill, S. L. (2013). Manual experience shapes object representations. Psychological Science, 24(6), 909-919. https://doi.org/10.1177/09567976124 64658

Zwaan, R. A. (2016). Situation models, mental simulations, and abstract concepts in discourse comprehension. Psychonomic Bulletin and Review, 23(4), 1028-1034. https://doi.org/10.3758/s13423-0150864-X 
Zwaan, R. A., \& Madden, C. J. (2005). Embodied sentence comprehension. In D. Pecher \& R. A. Zwaan (Eds.), Grounding cognition: the role of perception and action in memory, language, and thinking (pp. 224-245). Cambridge University Press. https://doi.org/10.1002/acp.1193

Zwaan, R. A., \& Radvansky, G. A. (1998). Situation models in language comprehension and memory. Psychological Bulletin, 123(2), 162185. https://doi.org/10.1037/00332909.123.2.162 


\section{Endnotes}

i We also collected ratings for the spatial locations of the whole sentence fragments. Participants rated the spatial position of these sentences independently of how they might be completed. Entering these sentence spatial locations as predictors yielded the same effect with no effect for presentation direction and even stronger increases in slope for each level of spatial location from 1 (down) to 7 (up), $(\beta=0.38[0.27 ; 0.49], \mathrm{t}=6.78, \mathrm{p}<.001)$.

ii Sample size for Experiment 2 was based on preliminary results of Experiment 1 hinging on spatial rating data for the complete set of produced nouns stemming from three subjects only. This analysis yielded a significant effect of presentation direction for cases with high semantic similarity between sentence noun and produced noun. Based upon this finding, sample size for Experiment 2 was estimated (see preregistration). Even though the preliminary results turned out the be spurious after completing the spatial rating with 37 raters, we ran the second experiment with the originally planned sample size.

iii A 9-point Likert scale for prerating of experimental items for Experiment 2 was chosen as we assumed that a wider range would better pick up on the big real word differences in spatial locations. However, as suggested in several methodological papers, 7-point Likert scales seem to be yielding the best reliability (Cicchetti et al., 1985; Finn, 1972; Oaster, 1989; Ramsay, 1973), we again chose a 7-point Likert scale for the rating of the produced nouns as this also enables direct comparison of results from Experiment 1 and 2. iv While 35 participants took part in Experiment 1 with 90 stimulus sentence, 72 participants took part in Experiment 2 with 60 stimulus sentences. Thereby, the total amount of potentially produced words which had to be rated already went up by ca. $25 \%$. Furthermore, several of the raters in Experiment 1 gave us the feedback that they found it annoying to rate spatial locations of seemingly equivalent objects. Our decision to only let people rate one version of near-synonyms thereby served both the purpose of making raters more willing to cooperate and of reducing the amount of words to be rated and thereby reducing the time needed for doing the rating and/or the amount of raters. For Experiment 2, two experimenters decided together whether two produced words could be handled as synonyms for the rating and in case of doubt both versions were kept in the rating. For this decision, we always kept in mind whether two words would refer to the same type of object and whether the use of one word version vs. the other could potentially have an impact on how far up or down in the world other people might perceive the word's referents.

$\mathrm{v}$ We deviated from the preregistered analysis plan of analyzing the impact of semantic similarity in bins of $10 \%$-percentiles for two reasons. Firstly, while cutting the whole set of similarities in percentile-bins would have permitted to run analyses with the same number of trials, it would have resulted in unequally spaced bins across the range of semantic similarity with the outer percentiles spanning a relatively large range of similarity values which is not informative with regard to the hypotheses. Secondly, splitting the whole set of similarities in ten equally spaced ranges would have resulted 
in outer bins not containing enough trials to run statistical analyses. Therefore, we resorted to splitting up the whole range of obtained similarity values using five levels. 


\section{Supplement}

\section{Table S1}

Experiment 1. LMM statistics for direction, sentence spatial location and cosine values serving as similarity measure computed with the semantic space de_wiki. Random effects for subjects were not included due to convergence errors.

\begin{tabular}{lllll}
\hline Variable & $b$ & $C I$ & $t$ & $p$ \\
\hline Intercept & 3.57 & {$[3.49 ; 3.66]$} & 83.05 & $<.001$ \\
$\begin{array}{l}\text { Direction } \\
\text { (Ascending-Descending) }\end{array}$ & 0.00 & {$[-0.09 ; 0.09]$} & -0.04 & .968 \\
$\begin{array}{l}\text { Sentence Spatial Location } \\
\text { Semantic Similarity }\end{array}$ & 0.20 & {$[0.11 ; 0.28]$} & 4.58 & $<.001$ \\
$\begin{array}{l}\text { Sentence Spatial Location : } \\
\text { Semantic Similarity }\end{array}$ & 0.20 & {$[-1.06 ;-0.25]$} & -3.15 & .002 \\
\hline
\end{tabular}

Note. The effect of spatial similarity cannot be interpreted meaningfully as the predicted values were spatial characteristics of the produced nouns. See Experiment 2, for discussion of a different impact of similarity on the predicted values

Table S2

Experiment 2. LMM statistics for direction, sentence spatial location and cosine values serving as similarity measure computed with the semantic space de_wiki

\begin{tabular}{|c|c|c|c|c|}
\hline Variable & $b$ & $C I$ & $t$ & $p$ \\
\hline Intercept & 3.72 & {$[3.61 ; 3.83]$} & 66.80 & $<.001$ \\
\hline $\begin{array}{l}\text { Direction } \\
\text { (Central-Descending) }\end{array}$ & -0.06 & {$[-0.15 ; 0.03]$} & -1.36 & .175 \\
\hline $\begin{array}{l}\text { Direction } \\
\text { (Ascending-Central) }\end{array}$ & -0.09 & {$[-0.18 ; 0.00]$} & -2.04 & .041 \\
\hline Sentence Spatial Location & 0.30 & {$[0.21 ; 0.39]$} & 6.40 & $<.001$ \\
\hline Semantic Similarity & -0.23 & {$[-0.55 ; 0.09]$} & -1.39 & 0.165 \\
\hline $\begin{array}{l}\text { Sentence Spatial Location } \\
\text { Semantic Similarity }\end{array}$ & 0.90 & {$[0.63 ; 1.18]$} & 6.39 & $<.001$ \\
\hline
\end{tabular}

Table S3

Predictability Experiment 2. Table containing the most frequently produced noun for each stimulus sentence together with its cloze value demonstrating that predictability as indicated by cloze values is not a likely source of the effects we found with cloze values being generally low. The rightmost column contains the total number of different concepts produced for each stimulus sentence. 


\begin{tabular}{|c|c|c|c|c|c|}
\hline $\begin{array}{l}\text { stimulus } \\
\text { number }\end{array}$ & sentence noun & $\begin{array}{l}\text { most frequently } \\
\text { produced sentence } \\
\text { ending }\end{array}$ & $\begin{array}{l}\text { absolute count } \\
\text { of the most } \\
\text { frequently } \\
\text { produced } \\
\text { noun }\end{array}$ & $\begin{array}{l}\text { cloze value } \\
\text { (relative } \\
\text { proportion of the } \\
\text { most frequently } \\
\text { produced noun) }\end{array}$ & $\begin{array}{l}\text { number of } \\
\text { different } \\
\text { concepts }\end{array}$ \\
\hline 1 & Meer & ein Strand & 9 & 0.125 & 34 \\
\hline \multirow[t]{2}{*}{2} & Pool & eine Luftmatratze & 9 & 0.125 & 34 \\
\hline & & Wasser & 9 & 0.125 & \\
\hline 3 & Kanal & ein Boot & 14 & 0.194 & 37 \\
\hline 4 & Fluss & ein Fisch & 9 & 0.125 & 37 \\
\hline 5 & See & ein Boot & 8 & 0.111 & 40 \\
\hline 6 & Teich & ein Frosch & 14 & 0.194 & 29 \\
\hline 7 & Bach & ein Fisch & 21 & 0.292 & 28 \\
\hline 8 & Feld & ein Hase & 8 & 0.111 & 47 \\
\hline 9 & Ufer & ein Boot & 8 & 0.111 & 42 \\
\hline 10 & Strand & Sand & 8 & 0.111 & 30 \\
\hline 11 & Wiese & eine Blume & 15 & 0.208 & 38 \\
\hline 12 & Straße & ein Auto & 23 & 0.319 & 28 \\
\hline 13 & Kreuzung & eine Ampel & 26 & 0.361 & 17 \\
\hline 14 & Lichtung & ein Reh & 16 & 0.222 & 35 \\
\hline 16 & Garten & eine Blume & 15 & 0.208 & 45 \\
\hline 17 & Zelt & ein Schlafsack & 8 & 0.111 & 36 \\
\hline 18 & Sofa & ein Kissen & 15 & 0.208 & 22 \\
\hline 19 & Freibad & ein Sprungbrett & 9 & 0.125 & 31 \\
\hline 20 & Haltestelle & ein Bus & 31 & 0.431 & 18 \\
\hline 21 & Weide & eine Kuh & 21 & 0.292 & 21 \\
\hline 22 & Baustelle & ein Bagger & 14 & 0.194 & 30 \\
\hline
\end{tabular}




\begin{tabular}{|c|c|c|c|c|c|}
\hline 23 & Bahnhof & ein Zug & 31 & 0.431 & 26 \\
\hline 24 & Zug & ein Gleis & 5 & 0.069 & 26 \\
\hline 25 & Garage & ein Auto & 29 & 0.403 & 23 \\
\hline 26 & Eingang & eine Tür & 22 & 0.306 & 22 \\
\hline \multirow[t]{4}{*}{27} & Terrasse & die Sonne & 5 & 0.069 & 40 \\
\hline & & ein Stuhl & 5 & 0.069 & \\
\hline & & ein Vogel & 5 & 0.069 & \\
\hline & & eine Blume & 5 & 0.069 & \\
\hline 28 & Innenhof & ein Fahrrad & 8 & 0.111 & 41 \\
\hline 29 & Park & ein Hund & 15 & 0.208 & 32 \\
\hline 30 & Küche & ein Kühlschrank & 10 & 0.139 & 38 \\
\hline 31 & Bus & eine Haltestelle & 7 & 0.097 & 33 \\
\hline 32 & Veranda & ein Garten & 7 & 0.097 & 36 \\
\hline \multirow[t]{2}{*}{33} & Ofen & ein Feuer & 10 & 0.139 & 31 \\
\hline & & ein Kuchen & 10 & 0.139 & \\
\hline 34 & Badezimmer & ein Spiegel & 12 & 0.167 & 18 \\
\hline 35 & Straßenbahn & ein Bus & 5 & 0.069 & 27 \\
\hline 36 & Café & ein Tisch & 13 & 0.181 & 20 \\
\hline 37 & Museum & ein Gemälde & 17 & 0.236 & 25 \\
\hline \multirow[t]{2}{*}{38} & Zaun & ein Hund & 5 & 0.069 & 41 \\
\hline & & ein Vogel & 5 & 0.069 & \\
\hline 39 & Schuppen & eine Schaufel & 19 & 0.264 & 30 \\
\hline 40 & Turnhalle & ein Ball & 14 & 0.194 & 29 \\
\hline 41 & Schule & eine Schultafel & 17 & 0.236 & 28 \\
\hline
\end{tabular}


Experience-driven Meaning in Production 46

\begin{tabular}{|c|c|c|c|c|c|}
\hline 42 & Haustür & ein Schlüssel & 9 & 0.125 & 27 \\
\hline 43 & Dschungel & ein Affe & 14 & 0.194 & 22 \\
\hline 44 & Schaufenster & $\begin{array}{l}\text { eine } \\
\text { Schaufensterpuppe }\end{array}$ & 29 & 0.403 & 20 \\
\hline 45 & Tisch & ein Teller & 12 & 0.167 & 30 \\
\hline 46 & Wald & ein Reh & 12 & 0.167 & 35 \\
\hline 47 & Haus & eine Tür & 13 & 0.181 & 38 \\
\hline 48 & Scheune & ein Pferd & 13 & 0.181 & 26 \\
\hline 49 & Garderobe & eine Jacke & 25 & 0.347 & 20 \\
\hline 50 & Kaufhaus & eine Kasse & 6 & 0.083 & 41 \\
\hline 51 & Brücke & Wasser & 10 & 0.139 & 32 \\
\hline 52 & Stadion & ein Tor & 8 & 0.111 & 21 \\
\hline 53 & Baum & ein Vogel & 12 & 0.167 & 29 \\
\hline 54 & Fenster & ein Vogel & 7 & 0.097 & 35 \\
\hline 55 & Straßenlaterne & Licht & 14 & 0.194 & 36 \\
\hline 56 & Balkon & eine Blume & 10 & 0.139 & 39 \\
\hline 57 & Leuchtturm & das Meer & 21 & 0.292 & 26 \\
\hline 58 & Gebirge & Berge & 10 & 0.139 & 34 \\
\hline 59 & Baumhaus & ein Vogel & 5 & 0.069 & 43 \\
\hline 60 & Aussichtspunkt & der Horizont & 5 & 0.069 & 37 \\
\hline
\end{tabular}

